\title{
Armed Conflict and Schooling in Rwanda: Digging Deeper
}

\author{
${ }^{1}$ Trinity College Dublin, Department of Economics, Arts Building, Dublin 2, Ireland, Phone: +35318961325 , Fax: +35316772503 , \\ E-mail: guarisoa@tcd.ie. https://orcid.org/0000-0003-2128-7322. \\ ${ }^{2}$ IOB Institute for Development Policy and Management, University of Antwerp (UA), Antwerp, Belgium
}

\begin{abstract}
:
We study how armed violence affected educational outcomes in Rwanda during the nineties, relying on two waves of population census data and on a difference-in-differences identification strategy. Results indicate that the violence caused a drop of about 1 year of education for the individuals exposed to the violence at schooling age. The drop was slightly larger for girls than for boys. While increased dropouts and school delays explain the drop in primary schooling, secondary schooling was mainly affected by a drop in enrolments. Finally, in a within-country analysis, we find no robust link between subnational variations in the drop in schooling and the intensity of the 1994 genocide - the most intense conflict event that took place in the country over the studied period. We present possible explanations for the observed patterns and provide related policy implications.
\end{abstract}

Keywords: Armed Conflict, Education, Genocide, Africa, Rwanda

JEL classification: I20, O15, O55

DOI: 10.1515/peps-2018-0033

\section{Introduction}

More than 280 armed conflicts took place since the end of World War II across more than 150 different countries (Dupuy et al., 2017). Better understanding how conflict affects human capital is crucial, in light of human capital's role as a key determinant of economic growth (e.g. Lucas, 1988), but also from a micro-perspective, given that negative shocks to human capital accumulation can have long-lasting individual welfare effects (e.g. Akbulut-Yuksel, 2014; Mincer, 1974).

In this study we analyze the impact of armed conflicts in Rwanda on educational outcomes and investigate the underlying channels. During the nineties Rwanda witnessed a dramatic sequence of violence, which reached its peak in 1994, when the genocide against the Tutsi minority claimed an estimated 800,000 lives in just 100 days. For our study we rely on fine-grained pre- and post-genocide population census data, and we structure the analysis in four parts.

First, we estimate the overall, nationwide impact of the violence on schooling, relying on a difference-indifferences (DiD) approach that compares schooling outcomes between the pre- and the post-genocide census round across a young and an older age cohort. Second, we study the heterogeneity of the impact across gender. Third, we analyze how changes in school enrolment, dropouts, and school delays contributed to the overall change in educational attainments. Finally, we look at within-country variations in the drop in schooling, and analyze whether and to what extent they relate to the local intensity of the 1994 genocide.

The estimates suggest that the armed violence in Rwanda caused a dramatic drop in schooling attainments, corresponding to roughly 1 year less of education, on average, for the cohort of individuals affected by the violence. The result passes a large set of robustness checks and falsification tests, including alternative specifications and correcting for migration as well as for the attrition in the data caused by the targeting of the (higher educated) Tutsi population during the genocide. Looking at heterogeneity across gender, we find that the drop in schooling was somewhat larger - by 1-3 months - for girls compared to boys. Regarding the channels, our results indicate that the drop in primary schooling attainments is driven by an increase in dropouts and significant delays in schooling, while enrolment remained virtually unaffected. For secondary schooling the situation is reversed, with a large drop in enrolment and relatively smaller (albeit still significant) increases in dropouts and delays. We also find the drop in secondary enrolment to be entirely explained by the drop in primary school completion. Finally, our subnational analysis does not reveal any evidence in support of localized effects of the 1994 genocide on schooling: based on various genocide-intensity proxies defined at low administrative levels, 
we find that areas little affected by the genocide witnessed similar drops in schooling as the most affected areas. This result remains when addressing the potential endogeneity of the genocide, and also when controlling for other forms of violence. We argue that, rather than the human toll taken in the killings (which displayed large subnational variation), what underlies the large drop in schooling is the widespread disruption of service delivery that went with it, and that hit every corner of the small country.

This study provides three contributions to the existing literature. First, the use of population census data makes possible a very fine-grained analysis that allows us to conduct not only a detailed subnational analysis, but also to present one of the first comprehensive micro-empirical analysis of the consequences of armed conflicts on school enrolment, dropouts, and school delays, disaggregated by primary and secondary schooling. ${ }^{1}$ Second, these data combined with a revised empirical approach allow us to update the existing evidence on the impact of violence in the context of Rwanda (Akresh \& de Walque, 2011; UNESCO, 2010). More specifically, our results indicate that the drop in schooling attainments is larger than previously thought; and contrary to what was argued before, it is larger for girls than for boys, and is felt in a similar fashion across the entire country, rather than being concentrated in areas where the 1994 genocide was more intense. ${ }^{2}$ Thirdly, this study highlights the sensitivity of results to the use of different counterfactuals, thus underlining the importance of combining different empirical approaches to estimate the consequence of violence on schooling. For instance, in a setting like the one of Rwanda, exploiting only local variations in the intensity of the main conflict event (i.e. the 1994 genocide) to identify a counterfactual would lead to wrong conclusions.

With these contributions, this study adds to the conflict literature (see Blattman and Miguel (2010) for a comprehensive review) and, more specifically, to the growing body of micro-empirical studies that investigate the consequences of the violence on education (see Justino (2011) and Buvinić, Das Gupta, and Shemyakina (2014) for a review). This study also adds to the rich literature on the Rwandan conflicts (e.g. Agüero \& Majid, 2014; de Walque \& Verwimp, 2010; Guariso \& Verpoorten, 2014; Lopez \& Wodon, 2005; Rogall \& Yanagizawa-Drott, 2014; Serneels \& Verpoorten, 2015; Straus, 2006; Verpoorten 2012a; 2012b; 2012c; Verwimp, 2005; YanagizawaDrott, 2014).

The remainder of the paper is organized as follows. Section 2 provides background information on Rwanda. Sections 3, 4, and 5 present identification strategy, data, and results, respectively. Finally, Section 6 provides a discussion of the findings and highlights the main policy implications.

\section{Background}

\subsection{History}

The history of Rwanda is marked by tensions between the two major ethnic groups, Hutu and Tutsi. ${ }^{3}$ Under the Belgian colonization (from World War I until 1962), the Tutsi minority represented the political and economic elite of the country. When the country gained its independence in $1962 \mathrm{Hutu}$ took over power and established a one-party state. Over the following decades, recurrent episodes of violence against Tutsi fueled the ranks of those that moved to live in exile. In late 1990, the Rwanda Patriotic Front (RPF), an army founded by Tutsi refugees, invaded Rwanda from the North. This led to a period of intermittent hostilities and negotiations with the Rwandan government, until a peace agreement was reached in 1993.

Peace only lasted until April 1994, when the plane carrying the Hutu President Habyarimana was shot down and genocide broke out. Within a few days, extremist Hutu militia groups, such as Interhamwe and Impuzamugambi, the Rwandan Armed Forces (FAR), and Rwandan police forces mobilized the civilian Hutu population to massacre the Tutsi minority and, to a lesser degree, Hutu who opposed the extremists. The civil war between the RPF and the Rwandan government restarted and intensified. By the end of June 1994, the RPF had taken control of the country, putting an end to the ethnic cleansing of Tutsi. Relative peace was established, although the RPF engaged in reprisal killings, and militias from the old regime who had fled across the border to DR Congo engaged in insurgencies in the North-West till the late nineties (African Rights, 1998).

During the nineties Rwanda thus experienced distinct forms of violence, which were concentrated in different geographical areas, had different durations, and varied in terms of their human death toll. While the civil war was prolonged and took place in most of the Northern and Eastern Provinces, as well as in the Center; the genocide against Tutsi was concentrated in 100 days and most intense in the South; and the (counter)insurgencies occurred sporadically in the period 1994-1998 in the North-Western Provinces. It is estimated that the total death toll in the nineties amounts to more than a million, with the largest direct death toll attributed to the genocide (Verpoorten 2005; 2012c). More than 100,000 civilians were convicted in the following years for crimes related to the genocide. The violence also pushed more than 2 million people to leave Rwanda and seek refuge in neighboring countries. The large majority of these refugees, however, returned to their homes within 
the coming few years, and by 2002 the UNHCR estimates that only roughly 75,000 refugees remained outside Rwanda (UNHCR, 2004).

\subsection{The education system}

The education system in Rwanda has traditionally been structured in $6+6+3 / 4$ years: 6 years of primary school, 6 years of secondary school (divided in 3 years of lower secondary and 3 years of upper secondary) and 3 or 4 years of higher education. Primary school is supposed to start at age 6, and students are therefore expected to move to secondary school at age 12. According to the 1991 census, however, the majority of the students in Rwanda transited from primary to secondary school between 13 and 14 years (Figure 6). Up until 2003, families had to pay school fees of 300 RWF (about \$0.6) per primary schooling term, and 4,500 RWF (about \$8.4) per secondary schooling term.

Schooling infrastructures were severely affected by the violence of the nineties. It is estimated that Rwanda had 1884 primary schools and 280 secondary schools (including both private and public ones) before the 1994 genocide. By October 1994, right after the end of the genocide, only 648 primary schools were operating and all schools were reported to be looted and pillaged (MINEPRISEC/MINESUPRES, 1994). As a consequence of the disruption caused by the violence, also government resources for education dried up, resulting in a 33\% decline of total spending on education over the period 1987-1996 (Table 1). Since a large share of those resources got directed to rebuilding schools damaged by the conflicts, current spending declined even more, by $54 \%$ over the same period. ${ }^{4}$

Table 1: Government spending on education, 1981-2001.

\begin{tabular}{lrrr}
\hline & & \multicolumn{2}{r}{ Spending on education } \\
\cline { 3 - 4 } Year & GDP & & as \% of GDP \\
\cline { 3 - 4 } 1981 & 100 & Total & Current \\
1982 & 102 & $n a$ & 2.7 \\
1983 & 108 & $n a$ & 3.0 \\
1984 & 103 & 3.3 & 3.2 \\
1985 & 108 & 3.1 & 3.2 \\
1986 & 114 & 3.5 & 3.2 \\
1987 & 114 & 3.5 & 3.2 \\
1988 & 119 & $n a$ & 3.1 \\
1989 & 119 & $n a$ & 3.0 \\
1990 & 116 & $n a$ & 2.9 \\
$1991-1995$ & 94 & $n a$ & 2.0 \\
1996 & 83 & 3.2 & 2.0 \\
1997 & 95 & 3.4 & 2.2 \\
1998 & 103 & 3.1 & 3.4 \\
1999 & 111 & 4.3 & 3.2 \\
2000 & 120 & 4.0 & 3.3 \\
\hline
\end{tabular}

The GDP values reported in the table are expressed as variation from 1981, which is selected as the base year. Original data on GDP (expressed in constant 2005 USD) is taken from the World Bank Development Indicators. Data on spending on education is instead taken from World Bank (2004). na = missing information.

\section{Identification strategy}

To study the effect of the violence on schooling attainments, we resort to a DiD estimation strategy. Relying on population census data collected before and after the conflict period, we identify a group of individuals whose schooling attainments were unaffected by the violence, and consider the evolution in their schooling attainments as a proxy for what the evolution would have been for the affected group, in the absence of the violence.

We define the affected group to include a young cohort of individuals that either were at schooling age when the violence reached its peak, with the 1994 genocide, or were expected to start school in the following years. 
We define the unaffected group to include a cohort of individuals expected to have completed school before the violence reached its peak, in 1994. The corresponding DiD empirical model is:

$$
y_{i, a, c, t}=\alpha_{1}\left(\text { Post-Genocide }_{t} \times \text { Young }_{a}\right)+\alpha_{2} \text { Post-Genocide }_{t}+\mathbf{X}_{i, c, t} \Delta+\eta_{a}+\pi_{c}+\varepsilon_{i, a, c, t}
$$

where $y_{i, a, c, t}$ indicates the number of years of schooling completed by individual $i$, of age $a$, living in administrative unit $c$ (for Commune), at time $t$; Post-Genocide is an indicator variable for being in the post-genocide census round; Young is an indicator variable for being in the affected cohort; $\mathbf{X}$ is a vector of individual- and householdlevel characteristics likely to influence the level of education of the individual, which will be detailed below; $\eta$ and $\pi$ represent the age and administrative unit fixed effects, respectively; and $\varepsilon$ is the error term. Standard errors will be always clustered at the level of the administrative units. A negative (positive) estimate of the DiD coefficient $\alpha_{1}$ indicates that the young cohort in the post-genocide era completed on average less (more) years of schooling, compared to the young cohort in the pre-genocide era and relative to the difference in schooling between the old cohorts over the same period. ${ }^{5}$

To study whether the impact was different for girls compared to boys, we slightly modify the above equation, adding a three-way interaction term with the individual-level indicator variable for being female. Concretely, this means including the terms Post-Genocide P $\times$ Young $_{a} \times$ Female $_{i}$ (and all its components) to Eq. 1.

To estimate the changes in enrolment and dropouts we combine a graphical analysis with an empirical check. For the latter we refer to a similar set-up as Eq. 1, but consider different outcome variables. Rather than looking at years of schooling, we construct variables for enrolment and drop-outs on the basis of the past and present schooling status of individuals, i.e. whether they ever attended school and whether they are still studying.

To study the contribution of delays in education we abandon the $\mathrm{DiD}$ approach to estimate the following equation:

$$
A_{i, g, c, t}=\delta_{1} \text { Post-Genocide }_{t}+\mathbf{X}_{i, c, t} \Psi+\kappa_{g}+\tau_{c}+v_{i, g, c, t}
$$

where the new dependent variable $A_{i, g, c, t}$ indicates the age of child $i$ attending grade $g$ in Commune $c$, at time $t$, while $\kappa$ indicates grade fixed effects. The coefficient $\delta_{1}$ captures whether, across the different grades, students are on average older in the post-genocide period than in the pre-genocide period.

Finally, we investigate the localized effect of the violence by studying the subnational relationship between the intensity of the 1994 genocide and the drop in schooling. We rely on two different empirical strategies. First, we resort to a new DiDiD approach, adding a three-way interaction term (as well as all its components) to Eq. 1, in which the young age cohort in the post-genocide period is interacted with a measure of genocide intensity, available at the level of the administrative Communes. We run a large set of robustness checks for our results, controlling for Commune-specific time trends and adjusting for post-genocide migration, for selective killings during the genocide, and for relief programs in the post-genocide period. Second, we address the potential endogeneity of violence using an Instrumental Variable (IV) strategy. In this case, we only consider the 2002 census round, for which more fine-grained administrative units are available ${ }^{6}$, and we rely on the instrument proposed by Rogall (2015). The instrument captures exogenous variation in the transportation costs that perpetrators of the genocide had to bare to reach different villages, caused by the distribution of rainfall during the 100 days of the genocide. ${ }^{7}$ More formally, we estimate the following:

$$
\begin{gathered}
\text { Genocide-intensity } y_{s}=\varphi_{1} \text { Transportation-costs }{ }_{s}+\mathbf{C}_{i, s} \Omega+\mathbf{X}_{i, s} \Phi+\rho_{a}+\zeta_{c}+\xi_{i, a, s} \\
y_{i, a, s}=\varphi_{1}^{\prime} \text { Genocide-intensity }{ }_{s}+\mathbf{C}_{i, s} \Omega^{\prime}+\mathbf{X}_{i, s} \Phi^{\prime}+\rho_{a}^{\prime}+\zeta_{c}^{\prime}+\xi_{i, a, s}^{\prime}
\end{gathered}
$$

where Eq. 3 and Eq. 4 represents the first and second step of the IV analysis, respectively. Genocide-intensitys indicates a measure of genocide intensity that is defined at the administrative level s (for Sector); Transportationcosts indicates the exogenous instrument, while $\mathbf{C}$ includes a rich set of controls that help ensuring that the exclusion restriction is satisfied. ${ }^{8}$

Before estimating the empirical models, we still need to specify the affected group. For our baseline estimation we define it to include ages 6-25. In 2002, this cohort includes individuals that were 17 or younger at the time of the 1994 genocide. According to the 1991 census, the group aged 17 or younger embraced more than $90 \%$ of the student population at that time (Figure 6). Hence, we are rather confident that our 2002 young cohort includes most of the individuals that were attending school at the peak of the violence. We define the old cohort to include individuals aged 26-45, to bracket the same number of years as the young cohort. This means that 
the old cohort includes individuals that were 18-37 years old at the time of the genocide. To investigate the role played by school enrolments, drop-outs, and delays, we adjust the age threshold to be able to study these channels separately for primary and secondary education (cf. below and Appendix C). In all cases, we check the robustness of our results to different age thresholds.

\section{Data}

\subsection{Rwandan population census data}

The main source of data for our empirical analysis consists of two population census rounds collected in Rwanda in 1991 and 2002. For the analysis we consider a 10\% random draw from each census round. ${ }^{9}$ Restricting the analysis to individuals aged 6-45, leaves us with 468,475 observations from the 1991 census round and 499,203 observations from the 2002 round.

Figure 1 displays the number of (completed) years of schooling for the pre- and post- conflicts round, across age. The old age cohorts display systematically higher average years of schooling in the post-genocide round compared to the pre-genocide round, indicating that before the violence there was a positive trend in schooling in Rwanda. In sharp contrast, educational attainments of the cohorts below 22 years are lower in the postgenocide round, compared to the pre-genocide round, suggesting a negative effect of the armed violence that took place during the nineties.

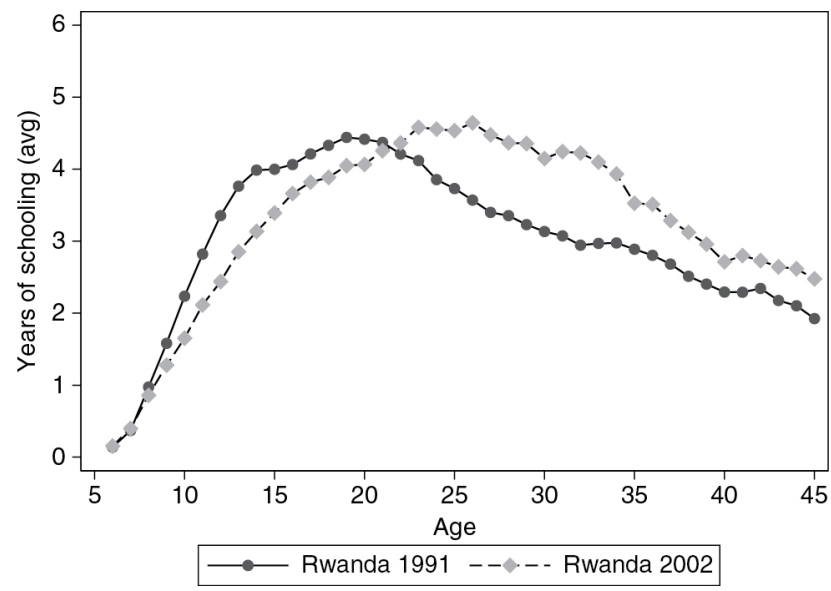

Figure 1: Years of schooling by age.

Source: Rwanda population census.

From the census data, we also construct indicator variables for school enrolment and dropouts, and a set of variables that are likely to affect educational attainments across individuals (included in the vector $\mathbf{X}$ in the above equations). These variables are: an indicator for being female; age and education of the household head; number of children under five living in the household; an indicator for residing in a rural area; and an indicator for being asset-rich ${ }^{10}$. Summary statistics are reported in Table 2.

Table 2: Summary statistics.

\begin{tabular}{|c|c|c|c|c|c|c|c|}
\hline & \multirow[b]{2}{*}{ Obs } & \multirow[b]{2}{*}{ Mean } & \multirow[b]{2}{*}{ Std.dev. } & \multicolumn{2}{|c|}{ Full Sample } & \multirow{2}{*}{$\frac{\text { Round I }}{\text { Mean }}$} & \multirow{2}{*}{$\frac{\text { Round II }}{\text { Mean }}$} \\
\hline & & & & Min & $\operatorname{Max}$ & & \\
\hline \multicolumn{8}{|l|}{ A. Rwanda - Full sample } \\
\hline Years of Schooling (YoS) & 967,678 & 3.06 & 2.89 & 0 & 16 & 2.92 & 3.19 \\
\hline Post-Genocide Round & 967,678 & 0.52 & 0.5 & 0 & 1 & 0 & 1 \\
\hline Young Cohort (6-25 years) & 967,678 & 0.68 & 0.46 & 0 & 1 & 0.67 & 0.69 \\
\hline Fermale & 967,678 & 0.52 & 0.5 & 0 & 1 & 0.51 & 0.54 \\
\hline Non-poor & 967,678 & 0.62 & 0.49 & 0 & 1 & 0.41 & 0.81 \\
\hline Age of Household Head & 967,678 & 42.48 & 13.28 & 10 & 100 & 42.63 & 42.34 \\
\hline YoS of Household Head & 967,678 & 2.96 & 3.22 & 0 & 16 & 2.72 & 3.19 \\
\hline \# Children Under Five & 967,678 & 1.12 & 1.01 & 0 & 10 & 1.24 & 1.01 \\
\hline Rural & 967,678 & 0.86 & 0.33 & 0 & 1 & 0.87 & 0.85 \\
\hline Student & 805,742 & 0.23 & 0.42 & 0 & 1 & 0.19 & 0.26 \\
\hline
\end{tabular}




\begin{tabular}{lrrrrrrr} 
Ever Been to Primary School & 805,742 & 0.73 & 0.44 & 0 & 1 & 0.7 & 0.77 \\
Ever Been to Secondary School & 805,742 & 0.12 & 0.32 & 0 & 1 & 0.12 & 0.11 \\
Dropped out from Primary & 805,742 & 0.27 & 0.45 & 0 & 1 & 0.26 & 0.29 \\
Dropped out from Secondary & 805,742 & 0.01 & 0.11 & 0 & 1 & 0.01 & 0.02 \\
B. Rwanda - Young Cohort & & & & & & & \\
Years of Schooling (YoS) & 662,740 & 2.96 & 2.67 & 0 & 16 & 2.94 & 2.98 \\
Post-Genocide Round & 662,740 & 0.52 & 0.5 & 0 & 1 & 0 & 1 \\
Fermale & 662,740 & 0.51 & 0.5 & 0 & 1 & 0.51 & 0.52 \\
Non-poor & 662,740 & 0.63 & 0.48 & 0 & 1 & 0.42 & 0.82 \\
Age of Household Head & 662,740 & 44.12 & 13.98 & 10 & 100 & 44.54 & 43.73 \\
YoS of Household Head & 662,740 & 2.82 & 3.17 & 0 & 16 & 2.58 & 3.04 \\
\# Children Under Five & 662,740 & 1.01 & 0.98 & 0 & 10 & 1.14 & 0.88 \\
Rural & 662,740 & 0.86 & 0.32 & 0 & 1 & 0.87 & 0.85 \\
Student & 502,702 & 0.36 & 0.48 & 0 & 1 & 0.33 & 0.4 \\
Ever Been to Primary School & 502,702 & 0.81 & 0.39 & 0 & 1 & 0.78 & 0.83 \\
Ever Been to Secondary School & 502,702 & 0.13 & 0.34 & 0 & 1 & 0.16 & 0.11 \\
Dropped out from Primary & 502,702 & 0.26 & 0.44 & 0 & 1 & 0.21 & 0.3 \\
Dropped out from Secondary & 502,702 & 0.01 & 0.1 & 0 & 1 & 0.01 & 0.01 \\
\hline
\end{tabular}

Notes: Panel A reports summary statistics for the full Rwandan sample (age 6-45). Panel B reports summary statistics for the Young Cohort (ages 6-25) in the Rwandan sample. Post-Genocide Round is an indicator variables that takes on the value of one for observations included in the 2002 census round. Education-related variables are only available for individuals aged 10 or above. Student captures whether the individual reported studying as main occupation. Ever Been to Primary (Secondary) School take on the value of one if the person is enrolled in or completed at least 1 year of Primary (Secondary) school. Dropped out from Primary takes on the value of one if the person completed at least the first year of primary school, but dropped out before completing the full cycle (equal to 6 years for Rwanda). Dropped out from Secondary takes on the value of one if the person completed at least the first year of secondary school, but dropped out before completing the first 3 years of secondary school (i.e. the lower cycle).

Population census data do not typically enjoy a good reputation, because collection methods and practices vary from country to country and because certain variables - such as citizenship and ethnicity - are often politicized. In the case of Rwanda, ethnicity is indeed politicized, which is reflected in the omission of ethnic identity in the 2002 census round, in line with the public rhetoric of national unity after the 1994 genocide. However, leaving ethnicity aside, the Rwandan census data has been shown to be very reliable. Verpoorten (2005) directly compared the 1991 census with the 1990 population data from the local administration, finding an almost exact match of the total number of women and men, which is indicative for the quality of both sources, as they were collected independently of each other. Furthermore, the information contained in the two census rounds is perfectly in line with the information contained in two rounds of DHS data collected around the same period, in 1992 and 2000 (see Appendix A for more details). The DHS data are firmly established in empirical research as a reliable source of information, mainly because of their standard and transparent approaches to data collection, cleaning and coding. However, while DHS data are representative at the Province level (there are 12 Provinces in Rwanda), census data are representative for the smallest administrative units, and for gender and age groups. This allows for a much more precise analysis.

\subsection{Violence intensity proxies}

To test for the existence of localized effects of violence, we rely on different conflict intensity proxies. Details on the sources, definitions, and summary statistics are reported in Table 17 and Table 18.

As described above, the 1994 genocide was by far the most dramatic conflict event, which caused an estimated death toll of around 800,000 people in barely 100 days. There are 5 different proxies for the intensity of the genocide that we can rely on: the share of Tutsi living in a Commune in 1991, the location of mass graves, the estimated genocide-related death rate, the share of perpetrators of genocide-related crimes, and the Genocide Excess Mortality Index (GEMI). All these 5 variables are positively correlated among each other (Table 19). We will repeat the analysis for each proxy separately as well as for their combination obtained through Principal Component Analysis. When relying on the DiDiD approach, we consider all measures at the level of the 145 Rwandan Communes, which we can match with both census data rounds. When performing the IV analysis, we descend instead to the Sector level to increase the power of our instrument. Consequently, we only use the 2002 census round and focus on the measure capturing the share of perpetrators of genocide-related crimes, which is also available at that more refined level.

For the other events in the Rwandan conflict cycle - civil war, insurgency and counter-insurgency operations, and refugee crisis - proxies are much scarcer. In our analysis we will therefore consider what, to the best of our knowledge, are the only two measures available: the Non-Genocide Excess Mortality Index (non-GEMI) and the share of households that resettled from Burundi, Tanzania, or DRC. The first measure is borrowed from 
Verpoorten (2012a) and is used to proxy for the death toll caused by the other conflict events that took place in the country during the nineties. ${ }^{11}$ The second measure is instead generated using migration information contained in the 2002 census and is used to proxy for the intensity of the refugee crisis. The correlation between these variables and the genocide measures is mostly negative and low (Table 19), indicating that different Communes of Rwanda were hit by different forms of violence. Figure 12 visually illustrates the spatial variation for each one of the different conflict-related variables.

\section{Results}

\subsection{The overall drop in schooling attainments}

Table 3 reports the estimation results of Eq. 1, in which progressively more controls are included. Regression 3 represents our preferred model that includes the full set of controls and fixed effects. The estimated DiD coefficient $\alpha_{1}$ indicates that the young cohort in the post-genocide era completed on average 1.1 less years of schooling, compared to the young cohort in the pre-genocide era and relative to the difference in schooling between the old cohorts over the same period.

Table 3: Drop in years of schooling.

\begin{tabular}{|c|c|c|c|c|}
\hline \multirow[t]{2}{*}{ Dependent Variable: } & \multicolumn{4}{|c|}{ Years of Schooling (YoS) } \\
\hline & (1) & (2) & (3) & (4) \\
\hline Young $\times$ Post-Genocide & $\begin{array}{r}-0.715^{* * *} \\
(0.036)\end{array}$ & $\begin{array}{r}-1.167^{* * * *} \\
(0.038)\end{array}$ & $\begin{array}{r}-1.105^{* * *} \\
(0.031)\end{array}$ & $\begin{array}{r}-0.996^{* * *} \\
(0.039)\end{array}$ \\
\hline Young $\times$ Post-Genocide $\times$ Female & & & & $\begin{array}{r}-0.265^{* * *} \\
(0.029)\end{array}$ \\
\hline Post-Genocide & $\begin{array}{r}0.758^{* * *} \\
(0.050)\end{array}$ & $\begin{array}{r}0.852^{* * *} \\
(0.049)\end{array}$ & $\begin{array}{r}0.451^{* * *} \\
(0.023)\end{array}$ & $\begin{array}{r}0.307^{* * *} \\
(0.032)\end{array}$ \\
\hline Young & $\begin{array}{r}0.045 \\
(0.077)\end{array}$ & & & \\
\hline Controls X & & & & \\
\hline Fermale & & & $\begin{array}{r}-0.320^{* * *} \\
(0.025)\end{array}$ & $\begin{array}{r}-1.042^{* * *} \\
(0.034)\end{array}$ \\
\hline Non-poor & & & $\begin{array}{r}0.450^{* * *} \\
(0.016)\end{array}$ & $\begin{array}{r}0.451^{* * *} \\
(0.016)\end{array}$ \\
\hline Age of Household Head & & & $\begin{array}{r}0.030^{* * *} \\
(0.001)\end{array}$ & $\begin{array}{r}0.031^{* * *} \\
(0.001)\end{array}$ \\
\hline YoS of Household Head & & & $\begin{array}{r}0.381^{* * *} \\
(0.003)\end{array}$ & $\begin{array}{r}0.380^{* * * *} \\
(0.003)\end{array}$ \\
\hline \# Children Under 5 & & & $\begin{array}{r}-0.061^{* * *} \\
(0.008)\end{array}$ & $\begin{array}{r}-0.060^{* * *} \\
(0.008)\end{array}$ \\
\hline Rural & & & $\begin{array}{r}-0.392^{* * * *} \\
(0.062)\end{array}$ & $\begin{array}{r}-0.393^{* * * *} \\
(0.062)\end{array}$ \\
\hline Components of interactions & no & no & no & yes \\
\hline Admin Effects & no & yes & yes & yes \\
\hline Age Effects & no & yes & yes & yes \\
\hline$R^{2}$ & 0.01 & 0.18 & 0.39 & 0.40 \\
\hline $\mathrm{N}$ & 967678 & 967678 & 967678 & 967678 \\
\hline
\end{tabular}

The dependent variable records the number of completed years of schooling. Regression 4 also include all constitutive terms of the triple interaction, but coefficients are omitted for reasons of space. Post-Genocide is an indicator variables that takes on the value of one for observations included in the 2002 census rounds. Non-poor is an indicator variable for living in a household whose asset index is above the population mean. Robust standard errors in parentheses, clustered at the Commune level. There are 145 Communes in the sample. ${ }^{* * *} \mathrm{p}<0.01,{ }^{* *} \mathrm{p}<0.05,{ }^{*} \mathrm{p}<0.1$.

We check the robustness of our results to different age thresholds, rerunning Eq. 1 multiple times, each time changing the threshold by 1 year, covering the interval between 16 and 30 years. The left-hand panel of Figure 2 summarizes the results, showing that the estimated drop in educational attainments is very stable and ranges between 0.9 and 1.2 years. An alternative approach is to estimate the drop in schooling for each age separately. To do so, we rerun our model replacing the interaction between the post-genocide indicator and the youngcohort indicator with the full set of interactions with a separate indicator for each age included in the young cohort - i.e. from 6 to 25. The right-hand panel of Figure 2 reports the estimate of each coefficient together with 
the relative 95\% confidence interval. The figure shows that for each age included in the young cohort there is a significant drop in schooling attainments, which oscillates between 0.1 (age 25) and 1.7 years (age 13). Taken together, the two panels of Figure 2 show that the large and significant drop in schooling is not driven by a few specific groups and is robust to movements in the exact definition of the young age cohort. In addition, while acknowledging that it is difficult to define the "right" threshold, these figures lend support to our choice of including ages up to 25 in the young cohort, because this allows including in the affected group a large share of individuals that were likely to be hit by the violence at schooling age, and because estimates are very stable for changes in the neighborhood of that threshold.
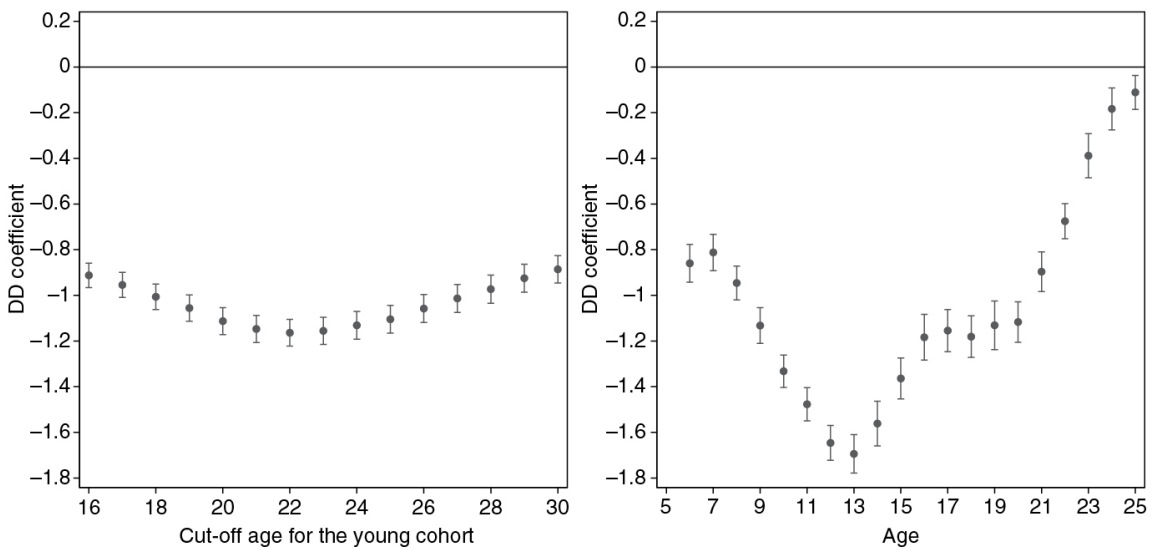

Figure 2: Drop in schooling attainments by age.

Notes: The two figures report the point estimates and the $95 \%$ confidence intervals from a set of regressions based on regression 3 in Table 3. See the main text for details.

In Appendix $C$ we report a rich set of additional checks to validate our finding: (i) we perform a falsification check by considering only cohorts whose schooling attainments should not have been affected by the genocide; (ii) we use the evolution in schooling attainments for a young cohort in other EAC countries to construct an alternative counterfactual; (iii) we enrich the model with commune time trends; (iv) we adjust for post-genocide migration; (v) we adjust for selective killings during the genocide.

\subsection{Boys versus girls}

Regression 4 of Table 1 estimates Eq. 1, augmented with the three-way interaction term Post-Genocide P $_{t}$ Young $_{a}$ $\times$ Female $_{i}$ (and all its components). The estimated coefficient of the triple interaction term indicates that the drop in schooling was 0.27 years larger for girls than for boys. As boys started from a much higher level of schooling, this translates in a larger gap in proportional terms: $31 \%$ drop for girls compared to 15\% drop for boys. Also in this case the result is robust to different definitions of the young cohort and is not driven but any specific age group (Figure 7).

The result, however, rests on the assumption that, had the violence not taken place, the difference in the 1991-2002 evolution in schooling attainments between girls and boys in the young cohort would have been the same as the difference in the evolution for girls and boys in the old cohort over the same period. This assumption may be questionable, as a catch-up process of girls' schooling had taken off in Rwanda over the previous decade, and this process may have slowed down or accelerated. ${ }^{12}$ We therefore rerun the analysis dropping the comparison with the old cohort and considering instead individuals in the young cohort in the other three EAC countries. We still find a significant, albeit smaller, drop in schooling for girls compared to boys, equal to 0.1 years (Table 12 ).

Overall, our analysis clearly indicates that both girls and boys suffered the consequences of the conflicts in Rwanda. The estimates suggest that girls attainments' experienced, if anything, a larger drop, although the difference is small.

\subsection{Lower enrolment, dropouts, or delays?}

The large drop in schooling attainments that was estimated in the previous sections can be due to children that do not enroll in school (HP1), students that drop out from school (HP2), or students that delay their education (HP3). ${ }^{13}$ 
We start by focusing on primary schooling. We rely on a set of simple figures to shed light on the importance of the three different channels, while full details of the regression analysis are reported in Appendix D. Figure 3A gives enrolment rate by age, i.e. the share of individuals that are recorded as students or that completed at least 1 year of school. The figure, which starts at age 10 because the census does not give student status for younger ages, shows that the enrolment rate has been constantly increasing in Rwanda over time. In particular, compared to 1991, individuals of all ages in 2002 were more likely to attend school. Figure 3B provides information on dropouts. Considering only individuals that ever attended school, it shows for each age above 13 (i.e. the age at which students are expected to complete primary school) the share of those that dropped out before completing the primary schooling cycle (6 years). The slope of the 1991 line indicates that dropouts were declining over time. However, for the 2002 line we observe a clear peak in drop-outs between ages 15 and 24, an interval that brackets individuals that were likely to be enrolled in school at the peak of violence (7-16 years old in 1994). Adopting the simplifying approximation that each student started primary school at age 6 and completed one grade per year, this pattern implies that dropouts were concentrated around the years 1992-1998 (Figure 8). Finally, Figure $3 \mathrm{C}$ reports the average age of students enrolled in primary school for grades $2-6 .{ }^{14}$ The average age of students is significantly higher in 2002 than in 1991 for each one of the primary grades. For instance, students who attend the final grade of primary school are on average 14.7 years old in 2002 compared to 12.5 in 1991.
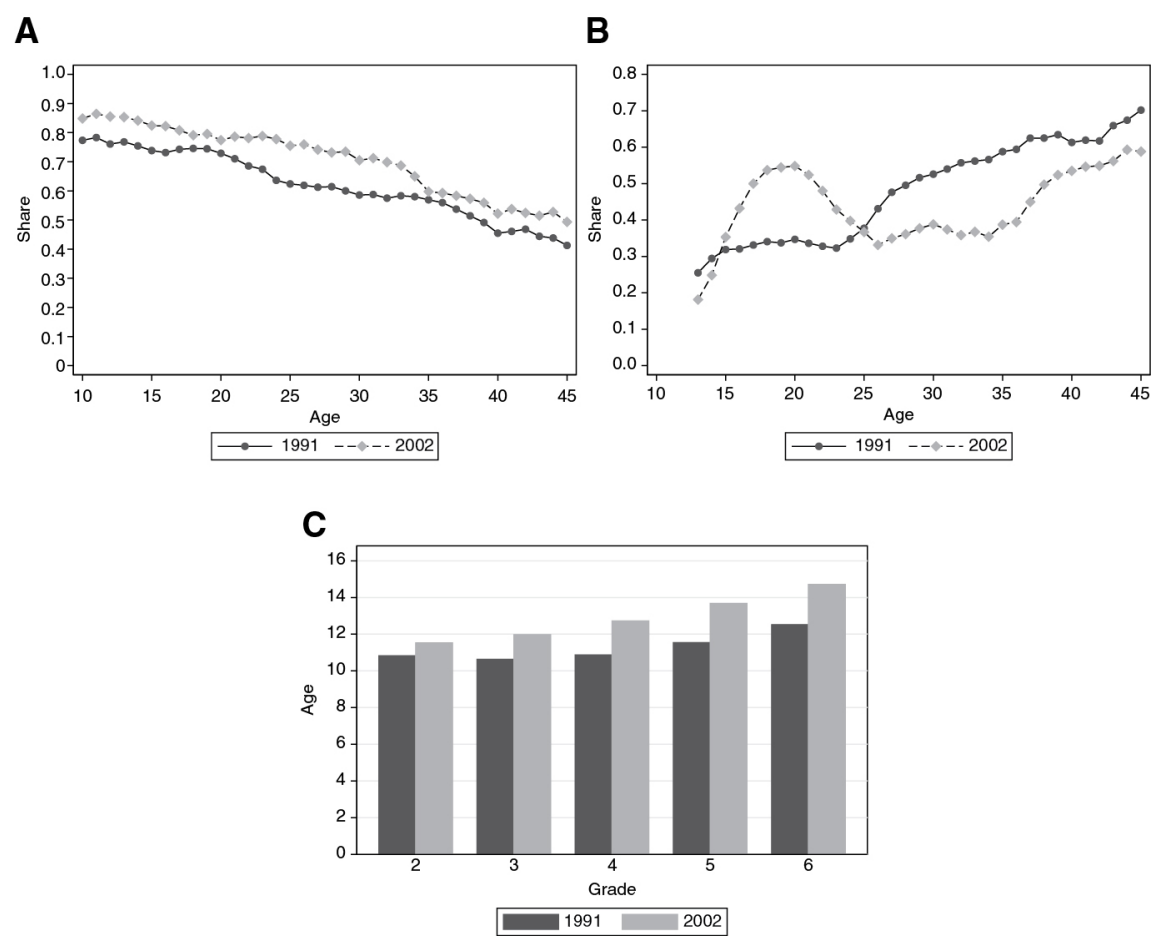

Figure 3: Channels - primary school. (A) Enrolment by age; (B) Dropout by age; (c) Age by grade.

Notes: Information on student status is only available from age 10. Source is Rwanda population census

Overall, these figures suggest that increased drop-outs (H2) as well as delays (H3) are responsible for the large drop in schooling attainments previously observed, while we do not observe any significant impact of the violence on primary school enrolment (H1). These results are confirmed in a regression analysis that builds on our DiD framework (Table 14): we observe no statistically significant effect on enrolments, but we find that individuals in the 2002 young age cohort that ever attended primary school were 23pp more likely to drop out before completing the 6-year cycle (compared to individuals of the same cohort in 1991 and relative to the difference in dropouts between the old cohorts), and that students enrolled in primary school in 2002 were on average almost 2 years older than students in the same grade in 1991.

Figure 4 presents a similar analysis for secondary schooling. Figure 4A gives enrolment rates by age. The figure starts at age 13, when students are supposed to enroll in secondary school. It shows that the enrolment rate in 2002 was systematically higher than in 1991 only for old age cohorts, not for the younger ones - i.e. those affected by the violence. The drop in secondary school enrolment for the affected cohort should not surprise given the increase in drop-outs from primary school observed above. When restricting the focus on individuals that actually completed primary school, the figure changes completely, showing that even for the youngest age cohorts enrolments (slightly) increased between 1991 and 2002 (Figure 4B). Figure 4C provides information on secondary schooling dropouts. Considering only individuals that ever attended secondary school, it shows for each age above 13 the share of those that dropped out before completing the first 3 years of secondary school 
(i.e. the lower cycle). The fact that the 2002 line lies mostly below the 1991 line indicates that secondary school dropouts were declining over time. However, similarly to what we saw for primary schooling, the 2002 line has a clear peak between ages 21 and 28, an interval that brackets individuals that were likely to be enrolled in secondary school at the peak of violence (13-20 years old in 1994). Finally, Figure 4D reports the average age of students enrolled in secondary school for grades 7-12. We observe relatively small differences in the average age between 1991 and 2002 across the secondary grades. Also in this case, all results are confirmed in a regression analysis (Table 14): we estimate a large and significant 11.5pp drop in secondary school enrolment, that however turns into a 4.9pp increase when restricting the sample to students that actually completed primary school; we estimate a significant 4.6pp increase in dropouts within the first 3 years of secondary school; and estimate that students enrolled in secondary schooling are on average 0.7 years older in the post-genocide era compared to the pre-genocide era. Despite being still significant, this age difference is less than half of the one we estimated for primary schooling, suggesting a smaller increase in school delays for students going to secondary school.
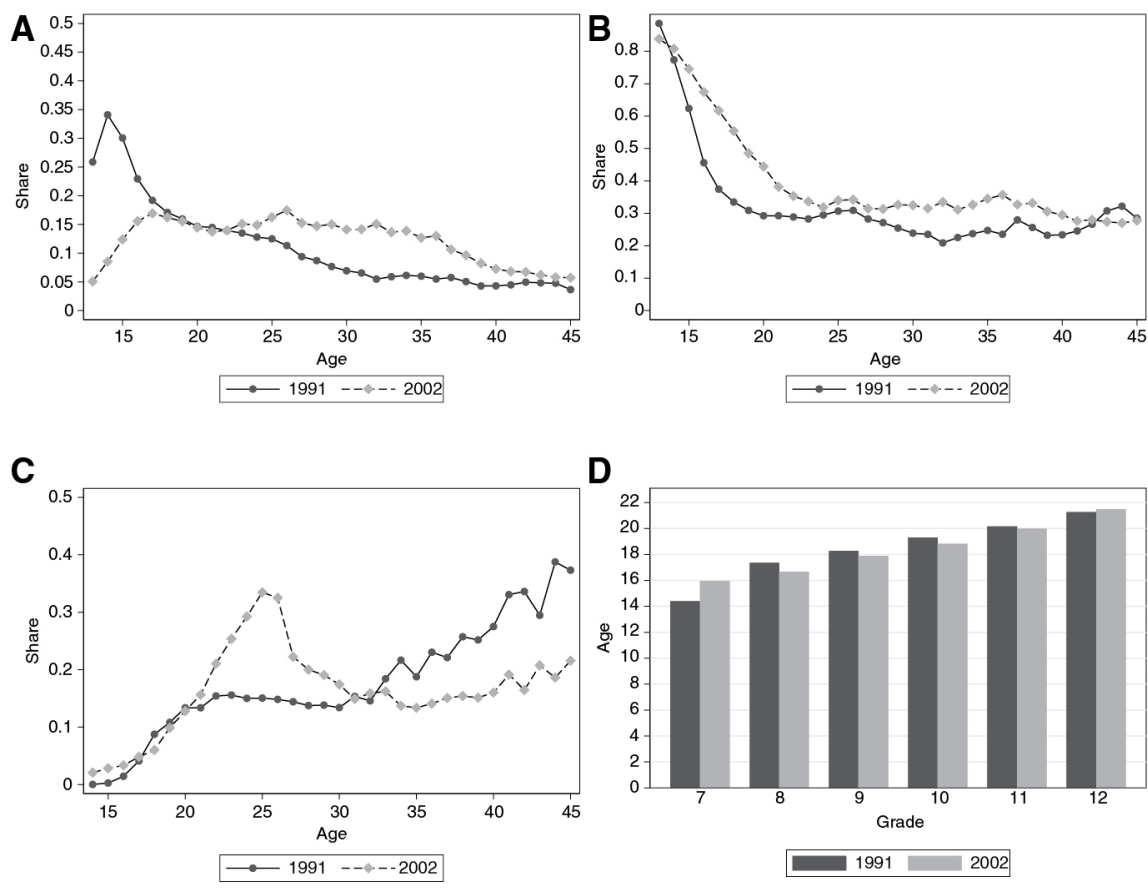

Figure 4: Channels - secondary school. (A) Enrolment by age (unconditional); (B) Enrolment by age (conditional); (C) Dropout by age; (D) Age by grade.

Notes: Information on student status is only available from age 10. Source is Rwanda population census.

Overall, our results indicate heterogeneity in the impact of the violence on schooling across primary and secondary education. ${ }^{15}$

When considering the heterogeneity of these channels by gender, we find evidence that the somewhat larger drop for girls that we identified previously is driven by a worsening in primary schooling outcomes. The estimates reveal a 10pp drop in primary enrolment rate and a 5.5pp increase in primary dropout rate for girls compared to boys, but no differential change in school delays (Table 16). When it comes to secondary schooling, the situation is reversed, with girls displaying a large 15pp increase in secondary enrolment rate (conditional on completing primary schooling) compared to boys, as well as a somewhat lower (3.6pp) secondary dropout rate. Differential change in school delays is again very small ( 0.17 years), although in this case the difference is statistically significant.

\subsection{Localized effects of violence?}

We take advantage of the fine-grained census data to examine whether the overall drop in schooling hides important subnational variations, and whether these relate to the intensity of the 1994 genocide across the country.

We start by performing a DiDiD analysis, adding to Eq. 1 a triple interaction term (as well as all its components) between the young cohort, the post-genocide period, and one of our six measures of genocide intensity (five original indicators, plus their combination through PCA). Regressions 1-6 of Table 4 show that, across the different measures, the DiDiD coefficients only turn significant when considering the number of mass graves in 
the Commune. Even in that case, significance is low (at 10\%) and the estimated effect $t$ is very small, indicating that one mass grave located in the Commune is associated with an additional 0.07 years drop in schooling (the average number of mass graves per Communes is 0.48 ). Thus, regressions $1-6$ overall suggest that individuals in the young cohort in areas more severely affected by the genocide experienced on average very similar drops in schooling attainments as individuals in areas that were relatively less affected by the genocide. 


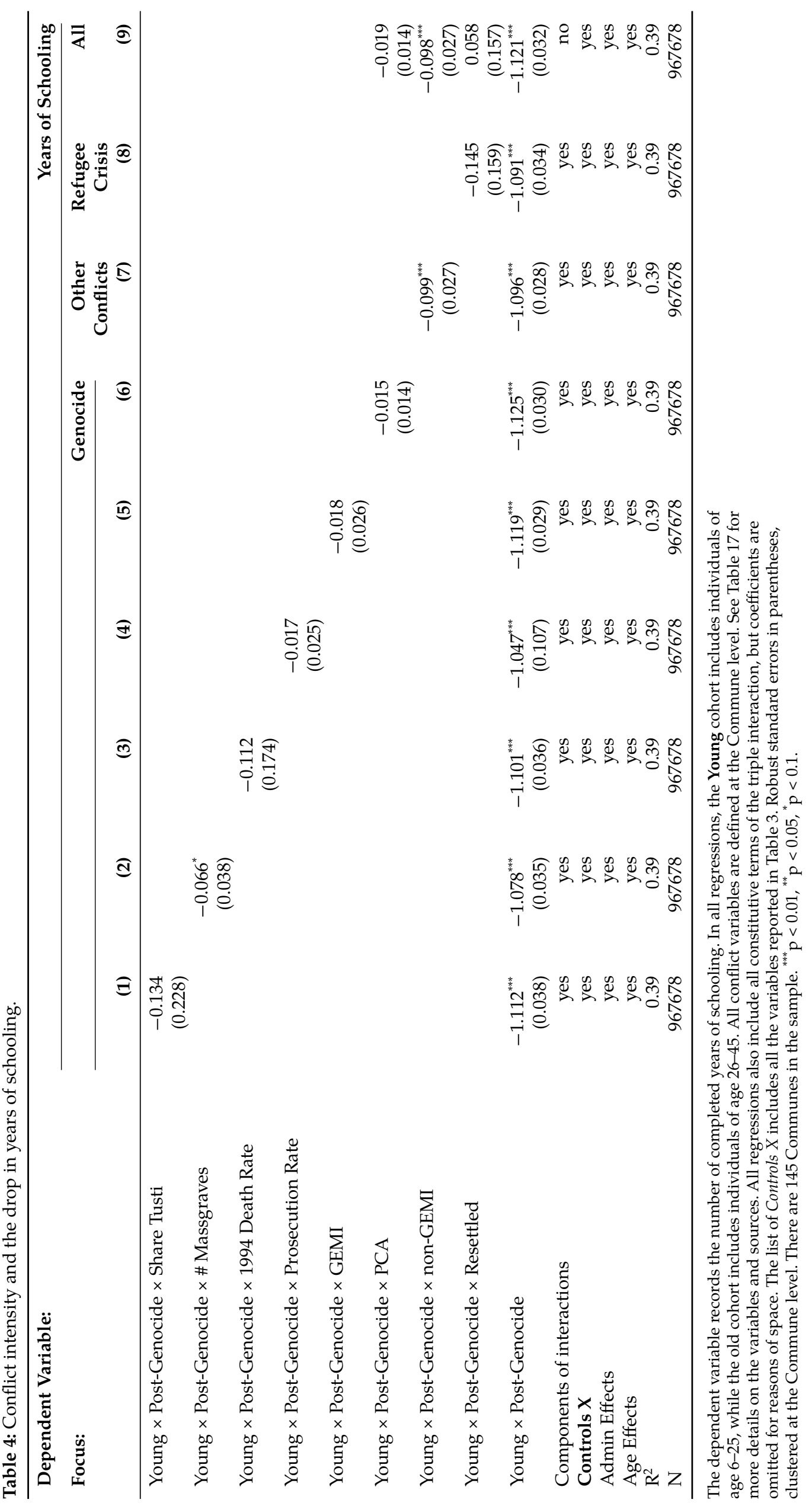


To account for possible confounding factors, we perform a set of robustness checks, described in Appendix E, in which we (i) enrich the model with commune time trends; (ii) adjust for post-genocide migration; (iii) adjust for selective killings during the genocide; (iv) adjust for relief programs in the post-genocide period; and (v) use the young cohorts in the other EAC countries to construct an alternative counterfactual. We find that the DiD coefficient - which captures the drop in schooling in areas that experienced no genocidal violence remains always very large and significant, while the DiDiD coefficients are very small and mostly not statistically significant. The mismatch between the drop in schooling and genocide intensity is also clear when one compares the spatial distribution of the estimated drop in schooling to the 1991 distribution of Tutsi (Figure 5). The spatial patterns do not match at all: for instance, many Northern Communes where the share of Tutsi was as low as $1.5 \%$ (compared to over 20\% in some of the Southern Provinces) still experienced large drops in schooling. ${ }^{16}$
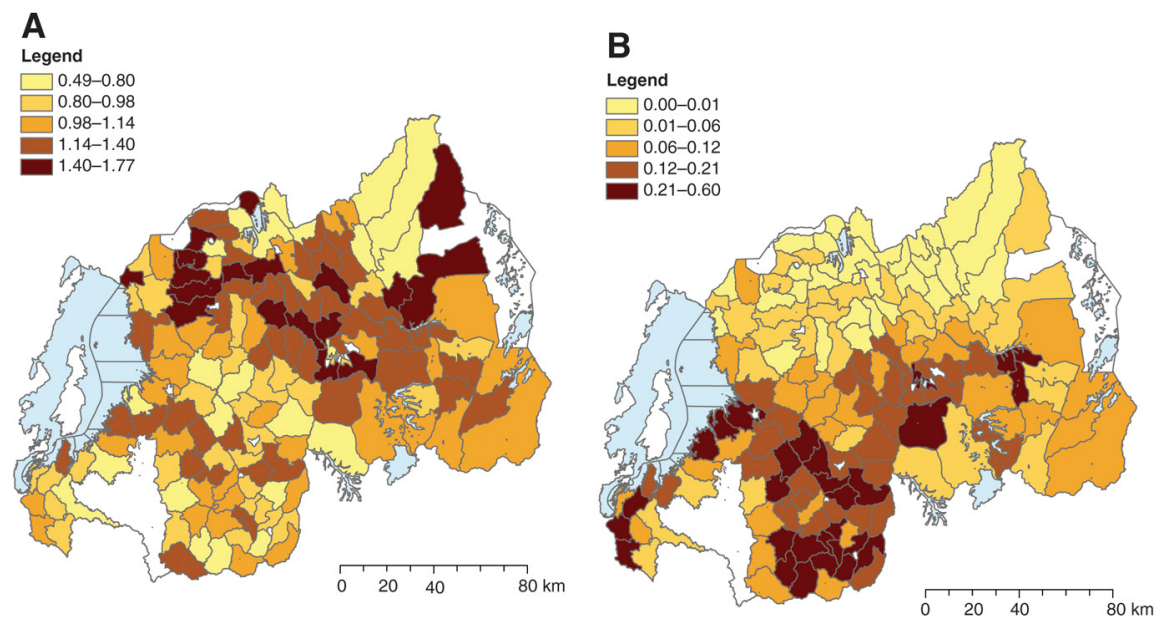

Figure 5: Spatial distribution of the drop in schooling and 1991 share of Tutsi. (A) Drop in Schooling; (B) Share of Tutsi, 1991.

Notes: Figure (A) shows the spatial distribution of the drop in schooling attainments across the different Communes of Rwanda. Values are obtained by estimating the DiD coefficient of regression 3 in Table 3 separately for each Commune. Figure (B) shows instead the spatial distribution of the share of Tutsi living in each Commune by 1991. Information is taken from the 1991 census. Different colors identify different quintiles, with a darker shade indicating a larger drop in schooling (Figure (A)) or a higher share of Tutsi (Figure (B)). No data are available for areas in white, which mostly include national parks and forests.

To further scrutinize this result, we abandon the DiDiD approach and switch to the IV strategy, in which we instrument the Sector-level share of genocide perpetrators with a rainfall-based measure of transportation cost, as described in Section 3. Table 5 reports the results. Given that the IV analysis is only based on the 2002 sample disaggregated at the Sector level, we first of all report the simple OLS results based on this new sample, including in the regression the full set of control variables borrowed from Rogall (2015). Results in column 1 confirm that, if anything, educational attainments were slightly higher in Sectors that recorded a larger share of genocide perpetrators. Regression 2 corresponds to Eq. 3 - i.e. the first stage of the IV analysis - and shows that, as expected, transportation costs are significantly and negatively related to the share of perpetrators in a Sector (F-test $=18.45$ ). Finally, regression 3 estimates the second stage of the IV regression, corresponding to Eq. 4. The estimated coefficient confirms that genocide intensity is not related to the drop in schooling attainments.

Table 5: IV regression.

\begin{tabular}{|c|c|c|c|}
\hline $\begin{array}{l}\text { Dependent Variable: } \\
\text { Model: }\end{array}$ & $\begin{array}{r}\text { Years of Schooling } \\
\text { OLS } \\
\text { (1) }\end{array}$ & $\begin{array}{r}\text { Prosecution Rate } \\
\text { OLS } \\
(2)\end{array}$ & $\begin{array}{r}\text { Years of Schooling } \\
\text { IV } \\
\text { (3) }\end{array}$ \\
\hline Prosecution Rate & $\begin{array}{r}0.006 \\
(0.008)\end{array}$ & & $\begin{array}{r}0.075 \\
(0.094)\end{array}$ \\
\hline Transportation Costs & & $\begin{array}{r}-0.531^{* * *} \\
(0.124)\end{array}$ & \\
\hline Controls X & yes & yes & yes \\
\hline Additional Controls & yes & yes & yes \\
\hline Admin Effects & yes & yes & yes \\
\hline Age Effects & yes & yes & yes \\
\hline F test & & 18.45 & \\
\hline
\end{tabular}


Sample is restricted to the 2002 census and to the young cohort (ages 6-25). The unit of observation is the Rwandan Sector. Prosecution rate indicate the (logarithm of the) number of Category 1 and Category 2 suspects for committing crimes during the genocide, weighted by the share of Hutu living in the Sector in 1991. Transportation Costs indicates the interaction between the distance from each Sector to the nearest major road and the amount of rain that fell over that distance path during the 100 days of the 1994 genocide. Controls $X$ include all the variables reported in Table 3. Additional Controls include the full set of controls used by Rogall (2015). See Rogall (2015) for more details. Robust standard errors in parentheses, clustered at the level of the Commune. There are 145 Communes in the sample. ${ }^{* * *} \mathrm{p}<0.01$, ${ }^{* *} \mathrm{p}<0.05,{ }^{*} \mathrm{p}<0.1$.

A possible explanation for the lack of evidence of any localized effects of the genocide is that areas that were not hit by the genocidal violence were still affected by the other conflict-related events that took place in the nineties, which were less intense, but longer-lasting. We test for this hypothesis by considering the nonGEMI index and the share of resettled households to proxy, respectively, for the intensity of the other armed conflicts that took place during the nineties and for the intensity of the refugee crisis. Columns 7 and 8 of Table 4 show the results for the DiDiD model using these alternative measures. The estimates suggest that Communes experiencing higher intensity in other armed conflict events experienced somewhat larger drops in schooling attainments: one standard deviation increase in the non-GEMI index leads to an additional drop of 0.1 years of schooling. We do not find instead any significant localized effect of the refugee crisis. These results are confirmed when jointly considering the different events - i.e. genocide, other armed conflicts, and refugee crisis - in the same regression (regression 9). Although our proxy for non-genocide conflict events is far from being perfect, these results suggest that the other armed conflicts that took place in the nineties in Rwanda had a somewhat stronger localized impact than the more intense, but short-lived genocide. However, the estimated additional effect is quite small, and results in Table 4 show that across all the different regressions, the coefficient of the interaction Post-Genocide $x_{t}$ Young $_{a}$ remains always very large (around -1.1 ). This means that even areas that experienced low direct exposure to any conflict-related event still suffered large drops in schooling.

An explanation that fits this pattern is one in which the nationwide disruption in the supply of education plays a leading role. Education supply is to a large extent determined by factors such as school buildings and teachers. ${ }^{17}$ According to at least three pieces of suggestive evidence, these factors were affected heavily and nationwide. First, while a 1994 report from the Ministry of Education (MINEPRISEC/MINESUPRES, 1994) indicates that as many as $65 \%$ of the 1,836 schools were damaged, needing urgent repair, a nationally representative community survey collected in 1999/2000 reveals no link between school damages and genocide intensity. ${ }^{18}$ Second, teachers had become a very scarce resource all over the country: many were killed, because they were Tutsi or part of the moderate Hutu elite; several others were imprisoned (having participated in the killings); and still others had moved abroad or to urban centers (Obura, 2003). The result was "the total erosion of faith in the education system", with less than half of qualified teachers remaining in the primary system after the end of the conflict (ibidem, p. 48). Looking at information on occupation in the 2002 census, we find no relation between the share of teachers and genocide intensity in a Commune. ${ }^{19}$ Third, the conflicts of the nineties heavily impacted the government budget, drying up resources for education. In addition, the limited budget was largely spent on the repair of buildings, further diminishing current spending to support the day-to-day running of the schooling system (see Table 1).

How to reconcile such nationwide disruption in the supply of education in the aftermath of the violence, with the evidence on the different channels presented above? In particular, one would expect such disruption to lead to an increase in dropouts - which we indeed observed - as well as to a drop in enrolment - which we instead did not observe. As mentioned earlier, however, we only have information on whether the individual was ever enrolled in school, while we do not know the age at enrolment. If children that were supposed to enrol in school around the time of the violence simply postponed their first enrolment, then we might indeed observe no drop in enrolment by 2002. Such delayed enrolments should also lead to a significantly higher average age of students per grade - which is indeed what we observed. To further look into this, we can focus on the age cohorts that were supposed to enrol in school at the time of the 1994 genocide or in the immediate aftermath - i.e. children aged 12-14 by 2002. Compared to their corresponding age cohorts in 1991, such cohorts in 2002 display significantly higher enrolment rates ( $87 \%$ vs. $81 \%)$, significantly lower droput rates ( $19 \%$ vs. $26 \%)$, but significantly lower years of schooling ( 2.8 vs. 3.7 years of schooling ). This is consistent with such cohorts enrolling in school at a later age in 2002 compared to 1991 and this is again also consistent with the fact that average age by grade in 2002 is almost 2 years higher than in $1991 .{ }^{20}$ 


\section{Discussion and conclusion}

Our analysis showed that armed conflicts that took place in Rwanda over the nineties caused a drop in schooling attainments of roughly 1 year, on average, for individuals aged $6-25$. While our estimate confirms the general finding in the literature, it is larger than what was previously estimated in the context of Rwanda (Akresh \& de Walque, 2011). The larger magnitude can be explained by the definition of the affected population. As shown in our analysis, the overall drop in schooling hit not only individuals that were at primary schooling age at the time of the violence, but also older cohorts of secondary schooling age. Including these cohorts in the comparison group, leads to underestimating the overall impact of the violence. ${ }^{21}$

The second set of results revealed that the conflicts dramatically affected both girls and boys, in line with our interpretation of a generalized disruption of the schooling system. However, our estimates also indicate that girls suffered an additional drop in schooling compared to boys. Although such additional drop is small in magnitude - 1-3-month - it translates in a larger gap in proportional terms, as boys started from a much higher level of schooling. This result corrects a previous opposite finding that was likely based on a specification in which constitutive components of the triple interaction term were erroneously omitted (see Appendix A for details). Such larger drop for girls also suggests that in the aftermath of the conflicts the limited available household resources were reallocated towards boys. This is not surprising in the context of a traditionally patriarchal society like Rwanda, and is in line with what studies have found in Tajikistan, India, and Guatemala (Shemyakina, 2011; Singh \& Shemyakina, 2016; Chamarbagwala \& Morán, 2011), although other studies have shown this result to be highly context-dependent (Buvinić, Das Gupta, \& Shemyakina, 2014).

The third set of results relates to what - to the best of our knowledge - is the first comprehensive microempirical analysis of the consequences of armed conflicts on school enrolment, dropouts and school delays, disaggregated by primary and secondary schooling. Concerning primary schooling, our results indicated that students were not less likely to enroll as a consequence of the conflicts. The large reduction in schooling attainments was instead driven by an increase both in delays in schooling (possibly related to delays in first enrolment) and dropouts. This puts the dramatic drop in education attainments in a somewhat different perspective, as it indicates that part of the drop is due to students postponing their education. Although more research is needed to identify the most effective policy, these findings suggest that to lessen the human capital shock in post-conflict settings, policies aimed at retaining primary school students (e.g. conditional cash transfer programs) and incentivizing their re-enrolment (e.g. the creation of specific programs for older students) are likely to be more effective than those aimed at lowering barriers to enrolment (e.g. providing school uniforms). For secondary schooling our results highlight a large drop in enrolment, which however can be fully attributed to the lower share of students completing primary school. When restricting the focus to students that actually completed the primary cycle, our results reveal a relative increase in secondary enrolment in the aftermath of the conflict, suggesting that conflicts reinforced a selection effect, by which the relatively more able and motivated students completed primary school and continued to secondary studies (this seems confirmed by the finding that school delays are less of an issue for students enrolled in secondary schooling).

Finally, in contrast with previous, less fine-grained, analyses (Akresh \& de Walque, 2011; UNESCO, 2010), our within-country analysis revealed no clear link between the drop in schooling and the intensity of the 1994 genocide. Even when taking into account other forms of violence that took place in the nineties, we still observed large drops in schooling attainments across the whole country, irrespectively of the local exposure to the violence. We argue that this points to the importance of supply-side factors such as infrastructures and teachers, rather than demand-side factors that correlate with the large human death toll. This finding aligns well with three other studies that find no or little impact of human death toll on education, and instead a large role for the quality and quantity of school buildings and teachers (Akbulut-Yuksel, 2014; Bruck, Di Maio, \& Miaari, 2013; León, 2012). This finding calls for caution in the design of post-conflict policies. For instance, after the end of the genocide there has been a proliferation of scholarship programs targeting especially regions where the genocide was more intense..$^{22}$ In light of our findings, such selective scholarship policies run the risk of missing out on students that would be equally in need for support, and may crowd out supply-side policies that could have a larger nationwide impact. The finding also calls for caution on the research front: the striking difference between the large drop in schooling attainments that we estimate at the country level and the absence of localized effect of the violence highlights the importance of combining different approaches when studying the consequence of armed violence. By only looking at variation in violence intensity within country, one might wrongly conclude that the violence had no impact - although this warning is likely to bare less relevance for more isolated conflict events in larger countries.

In terms of future research, more efforts are needed to unveil the exact mechanisms underlying the general channels that we highlighted in this work. In particular, our data and research design were ill-equipped to investigate which individual- or household- level characteristics determine the decision to enrol, drop out, or delay schooling. Alternative combinations of micro-level data and research design should set out to investigate 
this, so to guide the design of more targeted policies. In addition, our focus was on the quantity of education, i.e. the number of years of schooling, but we could not say anything about the quality of education. Rogall and Yanagizawa-Drott (2014) find some evidence of a worsening in the cognitive skills of children in more genocideaffected areas, despite an overall increase in living standards in their households. Further research is needed to better investigate the link between the quantity and the quality of education in the aftermath of violence.

\section{Acknowledgement}

We are grateful to Martina Björkman Nyqvist, Konrad Burchardi, Nathan Fiala, Kati Krähnert, Giulia La Mattina, Jean-François Maystadt, Andrea Ruggeri, Olga Shemyakina, Prakarsh Singh, Tim Williams and participants at the Jan Tinbergen European Peace Science Conference in Milan, the LICOS seminar in Leuven, the DSG seminar at IIES in Stockholm, the CSAE conference in Oxford, and the Annual Bank Conference on Africa in Berkeley for very helpful comments. We owe thanks to Nik Stoop for excellent research assistance and to the Rwandan National Census Service and Minnesota Population Center for making available the data used in this study. All errors and opinions expressed remain our own.

\section{Funding}

Andrea acknowledges financial support from VLADOC - 112 (VLIR-UOS) fellowship program, Funder Id: 10.13039/501100006338 and from PODER grant, funded under the Marie Curie Actions of the EU's Seventh Framework Programme, Funder Id: 10.13039/100011102 (Contract Number: 608109).

\section{Appendix A}

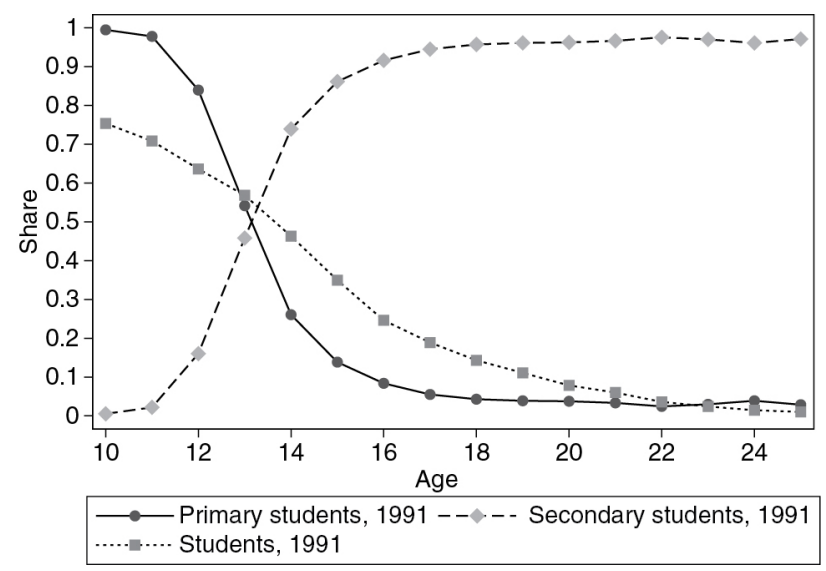

Figure 6: School enrolment in 1991.

Note: The figure shows three things: 1 ) the share of the population that is enrolled in school for each age from 10 to 25; 2) among the enrolled students, the share of those enrolled in primary school; 3) the share of those enrolled in secondary school. Student status is only available for individuals of age 10 or above. Source is the 1991 census round.
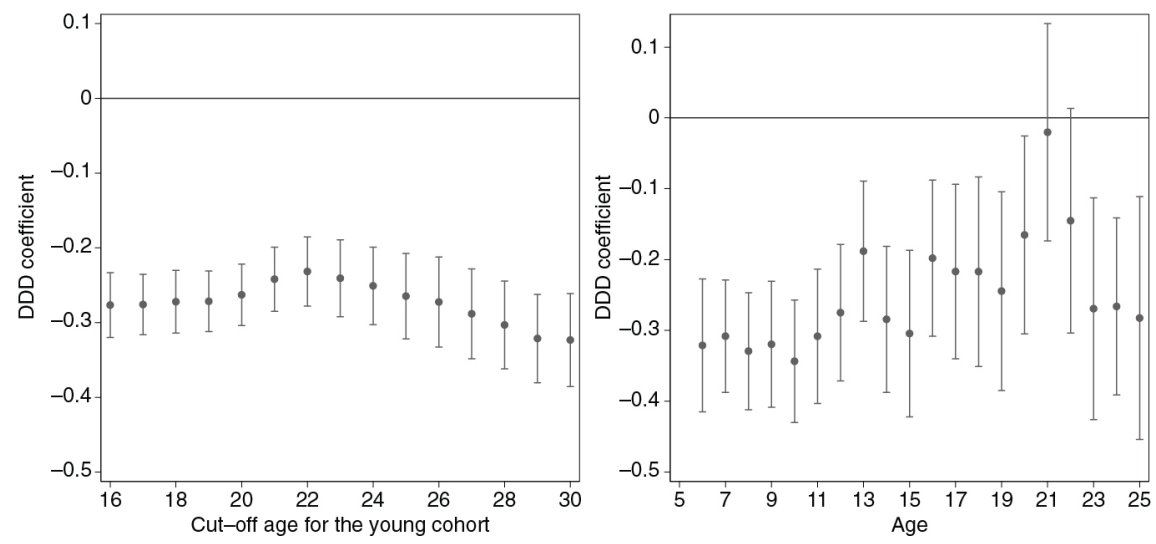
Figure 7: Heterogeneity across gender - estimates by age.

Notes: The two figures report the estimates from a set of regressions that are slight modifications of regression 4 in Table 3. The figure on the left shows the point estimates and the $95 \% \mathrm{CI}$ for the DiDiD coefficients of the interaction term between the Young cohort, the Post-Genocide Round, and the Female indicators, obtained in different regressions, in which the cut-off separating young and old age cohort moved between 16 and 30 years of age. The figure on the right shows instead the point estimates and the $95 \%$ CI for the different DiDiD coefficients obtained from a single regression in which the Young indicator in the triple interaction term (and in all its components) was replaced by the full set of individual age indicators - i.e. from age 6 to age 25 .

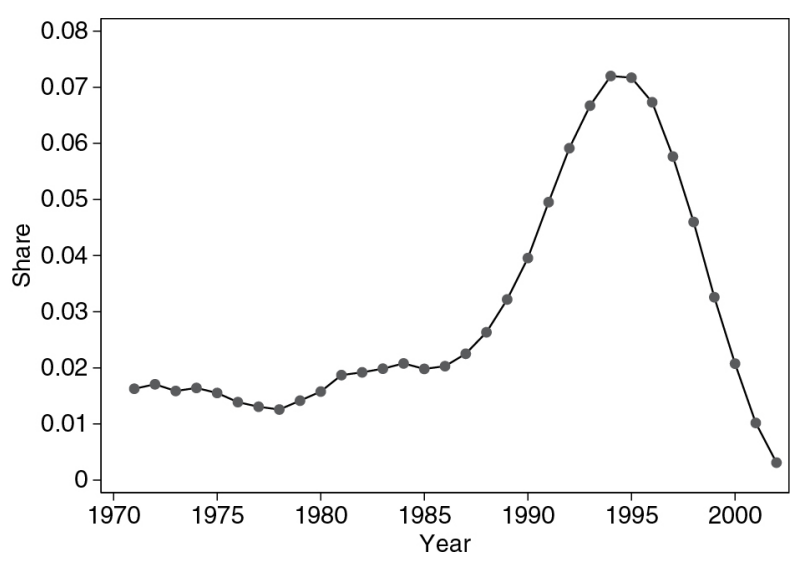

Figure 8: Estimated distribution of primary dropouts over time.

Note: The figure illustrates how primary dropouts are distributed over time in Rwanda, based on information contained in the 2002 census and under the assumption that each student started primary school at age 6 and completed one grade per year.

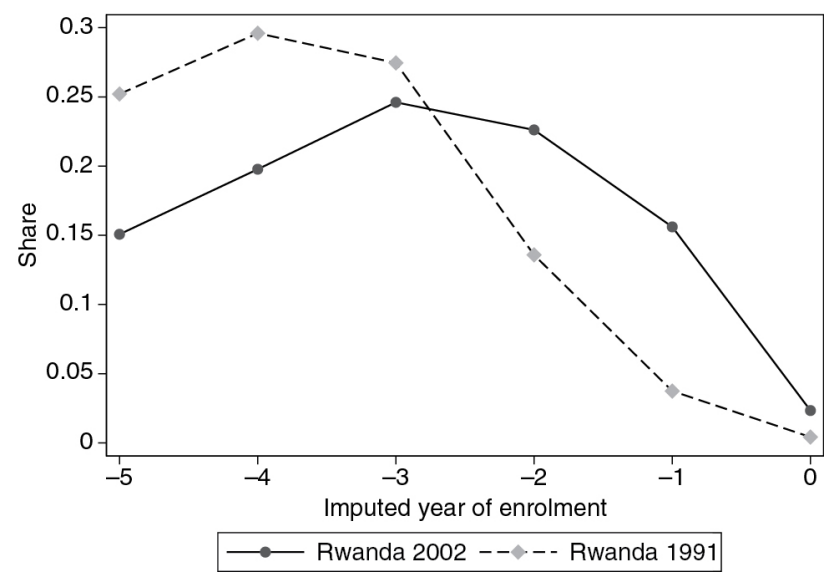

Figure 9: Estimated distribution of primary enrolment, 1991 vs. 2002.

Note: The sample is restricted to students that are enrolled in primary school in 1991 and 2002. The year of enrolment is then imputed by taking the difference between the census year and the years of schooling completed by the student - i.e. assuming that the student completed one grade per year. Values along the $\mathrm{X}$-axis indicate the imputed enrolment year expressed in terms of gap years from the census year (i.e. "-1" indicates 1990 for students in the 1991 census and 2001 for students in the 2002 census).

\section{Appendix B}

\section{Census vs. DHS data, and replication of Akresh and de Walque (2011)}

In Section 4.1 we justified the choice to use population census instead of DHS data, by referring to the larger number of observations, which make the data representative for small administrative units, as well as for subsamples of different age groups and gender. This Appendix provides more details concerning the comparison between the census and the DHS data. We then perform a replication exercise, using both census and DHS data, to illustrate how our analysis compares to the working paper by Akresh and de Walque (2011). 


\section{Census vs. DHS data}

Both Census and DHS provide two different rounds of data bracketing the main conflict period in Rwanda, with just few years of difference: the census rounds were collected in 1991 and 2002; the DHS in 1992 and 2000. We use the DHS data to generate the same variables that we use in our main analysis. The only exception concerns the asset index used to generate the non-poor indicator variable, for which we have to rely on somewhat different components. ${ }^{23}$ The summary statistics for the different variables are reported in Table 6, divided by source and data collection round.

In order to check the implication of using one source rather than the other, we run the main DiD regression (Eq. 1) on both datasets. Since the DHS data only provide information on the Province of residence of the respondent (and not on the Commune, as it is in the census data), we only include Province fixed effects in the regressions (this explains the small difference between some of the results reported in this table and those in the main text). We cluster standard errors at the enumeration level for the DHS and at the Commune level for the census regressions. Table 7 shows that results obtained with the two sources are very similar. When all controls are included in the regression, both sources indicate a drop in schooling attainments corresponding to about 1 year less of education for the young cohort in the post-genocide period. Importantly, also the coefficients of all the different control variables are very similar. This check highlights the reliability of the Rwandan census data and, given its much higher resolution compared to the DHS, supports our choice to focus on this source for our analysis.

\section{Comparison with Akresh and de Walque (2011)}

As explained in the text, our analysis presents some similarities with a widely cited study by Akresh and de Walque (2011) ${ }^{24}$ - from now on referred to as AdW. By relying on a DiD strategy and using the two DHS data rounds described above, AdW estimate a 0.56 years drop in schooling in Rwanda over the nineties. The authors also find the drop to be stronger for boys than for girls, and for individuals located in areas where the 1994 genocide was more intense. In this Section we discuss how our analysis compares to their study.

In replicating AdW results we stay as close as possible to their empirical set up, which differ from our own analysis in four ways. First, AdW define the young cohort as including ages 6-15 and the old cohort as including ages 16-35. Second, AdW define a slightly different asset index, relying on the larger set of asset variables included in the DHS dataset. ${ }^{25}$ Third, AdW consider fixed effects at the level of the 12 Provinces, rather than at the level of the 145 Commune, as the DHS dataset does not record the Commune of origin of the respondent. Finally, AdW include a control for the highest level of education attained by any member of the household, rather than the level of education of the household head.

Overall drop in schooling

We start performing a narrow replication of AdW results, using their exact same sources (DHS data) and set-up. Regression 1 in Table 8 reports the DiD estimate that AdW obtain in a simple model without any control $(-0.555)$. Regression 2 shows that in our narrow replication we obtain a very similar coefficient $(-0.572)$, although we cannot replicate $100 \%$ the exact same Figure. ${ }^{26}$ We then perform a scientific replication, using the census data. Regression 3 shows that the estimate we obtain $(-0.589)$ is again very close to the AdW result, despite the slightly different sample years (1992 and 2000 for the DHS versus 1991 and 2002 for the census data).

In the next step, we follow AdW and include in the empirical model the full set of controls, as well as Province and age fixed effects. The new estimate of the DiD coefficient reported by AdW is -0.421 (regression 4). In our narrow replication using DHS data we find a slightly larger coefficient of -0.529 (regression 5 ). The scientific replication using census data yields a higher estimate of -0.739 (regression 6) - although in this case data limitations force us to rely on a somewhat different asset measure. Overall, both our narrow and scientific replication so far broadly confirm the initial result of AdW of a large drop in schooling attainments.

One problem with the definition of the age categories used in the main specification of AdW is that the old age cohort (16-35) includes individuals that were still at schooling age when the genocide broke out. ${ }^{27}$ For instance, individuals aged 16-25 in 2002 were aged 8-17 in 1994. Since at that age many individuals were still attending school, their schooling attainments were likely affected by the violence as well. Including these individuals in the old cohort is therefore likely to lead to an underestimation of the effect of the violence. This is the reason why in our main specification in the text we enlarge the young cohort to include individuals of age 6-25 - meaning individuals that were 17 or younger when the genocide broke out. Once this is taken into account, as expected, we identify an overall drop in schooling that is larger than 1 year, i.e. almost twice as large as the one originally identified by AdW.

Effects by gender 
AdW also investigate whether the drop in schooling was larger for boys or girls. They do so by including in their model a triple interaction term Post-Genocide ${ }_{t} \times$ Young $_{a} \times$ Female $_{i}$. Differently from our analysis, however, they report a positive and significant DiDiD estimate (0.219, regression 7 or Table 8$)$, suggesting that the impact of the conflict on the schooling of girls is less negative than the impact for boys.

Why do we find the opposite results? We suspect the reason is that in the specification used by AdW two out of the three constitutive terms of the interaction effect are erroneously omitted (Young $\times$ Female ${ }_{i}$, and PostGenocide $_{t} \times$ Female $\left._{i}\right)$. In a narrow replication on the basis of DHS data and omitting the constitutive terms of the $\mathrm{DiDiD}$ we indeed find a similar positive coefficient (0.236, not reported). When we include all constitutive components of the triple interaction, we find instead a negative coefficient of -0.096 (regression 8), suggesting that, if anything, girls experienced a larger drop than boys - although the coefficient is not statistically significant at conventional levels. In the scientific replication using census data we estimate a similar negative DiDiD coefficient, equal to -0.136 (regression 9), which is significantly different from zero, confirming the additional schooling deficit for girls.

Thus, the result of AdW of a higher schooling deficit for boys is reverted when adding the constitutive components of the triple interaction terms. Our new findings point to an additional (albeit small) negative impact of conflict on the schooling of girls. Although in absolute terms the additional effect for girls is small, it becomes more than double in relative terms (30\% drop in schooling attainments for girls compared to a $15 \%$ drop for boys), as boys started from a much higher level of schooling, on average.

Localized effects of the genocide

AdW test whether the drop in schooling can be attributed to the 1994 genocide by estimating another DiDiD model in which the young age cohort in the post-genocide round is interacted with a measure of genocide intensity. In this case, the authors explicitly report including in the regression also all the constitutive components of the triple interaction.

However, AdW consider three different genocide intensity measures that are only defined at the level of the 12 Provinces: the proportion of days during which killings occurred in a Province in the months April-June 1994 (Measure A); an indicator variable taking on the value of one for the three Provinces with the highest number of killings in 1994 (Measure B); the number of mass graves and memorials per Province (Measure C). ${ }^{28}$ The DiDiD estimates obtained by AdW - and reported in Panel A of Table 9 - are all negative and significant at the $10 \%$ level (A:-0.024, B:-0.329, C:-0.023), pointing to a stronger negative impact on schooling in Provinces where genocide intensity was relatively higher.

We cannot replicate these results. As Panel B of Table 9 shows, in our narrow replication, using the same variables and specification, we obtain very different coefficients: A:0.705, B:-0.905, and C:0.018. It is not clear where these differences come from. Estimates are also very different when we replicate their approach using the population census data; the coefficients - reported in Panel C of Table 9 (A:0.190, B:0.026, C:0.005) - are all positive close to zero.

In an attempt to address the potential endogeneity of genocide intensity, AdW perform an IV estimation. The instrument they use is the Province-level distance to the Ugandan border and their IV coefficients are in line with their OLS results. Once again, we obtain very different results - mostly not statistically significant both for our narrow and for our scientific replication. ${ }^{29}$

Leaving aside the comparison with the results of AdW, our failure to establish a direct link between the drop in schooling and genocide intensity may be due to the fact that the conflict intensity measures defined at the Province level are too crude to properly capture variation in the intensity of the violence. This is why in our analysis we turned to consider alternative measures, all defined at the level of the 145 administrative Communes (and at the level of the 1432 administrative Sectors, in the case of the IV analysis). As our results have shown, however, we cannot identify any localized effects of the genocide. The IV analysis confirmed that areas where the intensity of the violence was relatively lower experienced a drop in schooling that is comparable to areas where the violence was more intense.

Table 6: Census vs. DHS - summary statistics.

\begin{tabular}{|c|c|c|c|c|c|c|c|}
\hline & & & & \multicolumn{2}{|c|}{ Full Sample } & \multirow{2}{*}{$\frac{\text { Round I }}{\text { Mean }}$} & \multirow{2}{*}{$\frac{\text { Round II }}{\text { Mean }}$} \\
\hline & Obs & Mean & Std.dev. & Min & Max & & \\
\hline \multicolumn{8}{|l|}{ Panel A. Census } \\
\hline Years of Schooling (YoS) & 967,678 & 3.06 & 2.89 & 0 & 16 & 2.92 & 3.19 \\
\hline Post-Genocide Round & 967,678 & 0.52 & 0.5 & 0 & 1 & 0 & 1 \\
\hline Young Cohort (6-25 years) & 967,678 & 0.68 & 0.46 & 0 & 1 & 0.67 & 0.69 \\
\hline Fermale & 967,678 & 0.52 & 0.5 & 0 & 1 & 0.51 & 0.54 \\
\hline Non-poor & 967,678 & 0.62 & 0.49 & 0 & 1 & 0.41 & 0.81 \\
\hline Age of Household Head & 967,678 & 42.48 & 13.28 & 10 & 100 & 42.63 & 42.34 \\
\hline YoS of Household Head & 967,678 & 2.96 & 3.22 & 0 & 16 & 2.72 & 3.19 \\
\hline
\end{tabular}




\begin{tabular}{|c|c|c|c|c|c|c|c|}
\hline \# Children Under Five & 967,678 & 1.12 & 1.01 & 0 & 10 & 1.24 & 1.01 \\
\hline Rural & 967,678 & 0.86 & 0.33 & 0 & 1 & 0.87 & 0.85 \\
\hline \multicolumn{8}{|l|}{ Panel B. DHS } \\
\hline Years of Schooling (YoS) & 52,082 & 3.17 & 3.22 & 0 & 16 & 3.21 & 3.15 \\
\hline Post-Genocide Round & 52,082 & 0.6 & 0.49 & 0 & 1 & 0 & 1 \\
\hline Young Cohort (6-25 years) & 52,082 & 0.7 & 0.46 & 0 & 1 & 0.67 & 0.71 \\
\hline Fermale & 52,082 & 0.52 & 0.5 & 0 & 1 & 0.51 & 0.53 \\
\hline Non-poor & 52,082 & 0.46 & 0.5 & 0 & 1 & 0.44 & 0.48 \\
\hline Age of Household Head & 52,082 & 43.09 & 13.68 & 7 & 98 & 44.3 & 42.29 \\
\hline YoS of Household Head & 52,082 & 3.48 & 3.83 & 0 & 16 & 3.26 & 3.63 \\
\hline \# Children Under Five & 52,082 & 0.83 & 0.83 & 0 & 5 & 0.87 & 0.81 \\
\hline Rural & 52,082 & 0.79 & 0.41 & 0 & 1 & 0.83 & 0.76 \\
\hline
\end{tabular}

Non-poor is an indicator for being above the population mean of an asset index, constructed by giving equal weights to different indicator variables that capture households characteristics. Due to data limitations, the index is constructed differently in the census and DHS samples. In the census sample it includes four variables: whether there is (any type) of toilet; whether the dwelling is owned by the household; whether there is a finished floor; and whether there is tiles or cement roof. In the DHS sample it includes instead only three variables: whether there is (any type) of toilet; whether there is a finished floor; and whether the household owns a radio. For the DHS sample, Round I refers to 1992 and Round II to 2000. For the census sample, Round I refers to 1991 and Round II to 2002.

Table 7: Census vs. DHS - regressions.

\begin{tabular}{|c|c|c|c|c|}
\hline \multirow{2}{*}{$\begin{array}{l}\text { Dependent Variable: } \\
\text { Source: }\end{array}$} & \multirow[b]{2}{*}{$\begin{array}{r}\text { Census } \\
\text { (1) }\end{array}$} & & \multicolumn{2}{|c|}{ Years of Schooling (YoS) } \\
\hline & & $\begin{array}{r}\text { DHS } \\
(2)\end{array}$ & $\begin{array}{r}\text { Census } \\
\text { (3) }\end{array}$ & $\begin{array}{r}\text { DHS } \\
\text { (4) }\end{array}$ \\
\hline Young $\times$ Post-Genocide & $\begin{array}{r}-1.172^{* * *} \\
(0.036)\end{array}$ & $\begin{array}{r}-0.991^{* * *} \\
(0.128)\end{array}$ & $\begin{array}{r}-1.082^{* * *} \\
(0.031)\end{array}$ & $\begin{array}{r}-0.939^{* * *} \\
(0.114)\end{array}$ \\
\hline Post-Genocide & $\begin{array}{c}0.838^{* * *} \\
(0.039)\end{array}$ & $\begin{array}{c}0.625^{* * *} \\
(0.167)\end{array}$ & $\begin{array}{c}0.537^{* * * *} \\
(0.023)\end{array}$ & $\begin{array}{c}0.453^{* * * *} \\
(0.092)\end{array}$ \\
\hline Controls X & & & & \\
\hline Female & & & $\begin{array}{r}-0.305^{* * *} \\
(0.025)\end{array}$ & $\begin{array}{r}-0.316^{* * *} \\
(0.026)\end{array}$ \\
\hline Non-poor & & & $\begin{array}{c}0.562^{* * *} \\
(0.011)\end{array}$ & $\begin{array}{r}0.560^{* * *} \\
(0.029)\end{array}$ \\
\hline Age of Household Head & & & $\begin{array}{c}0.030^{* * *} \\
(0.001)\end{array}$ & $\begin{array}{l}0.027^{* * * *} \\
(0.001)\end{array}$ \\
\hline YoS of Household Head & & & $\begin{array}{c}0.371^{* * *} \\
(0.003)\end{array}$ & $\begin{array}{r}0.330^{* * *} \\
(0.005)\end{array}$ \\
\hline \# Children Under 5 & & & $\begin{array}{r}-0.073^{* * *} \\
(0.008)\end{array}$ & $\begin{array}{r}-0.176^{* * *} \\
(0.017)\end{array}$ \\
\hline Rural & & & $\begin{array}{r}-0.240^{* * *} \\
(0.044)\end{array}$ & $\begin{array}{r}-0.585^{* * *} \\
(0.061)\end{array}$ \\
\hline Province Effects & yes & yes & yes & yes \\
\hline Age Effects & yes & yes & yes & yes \\
\hline $\mathrm{R}^{2}$ & 0.21 & 0.26 & 0.39 & 0.45 \\
\hline $\mathrm{N}$ & 967678 & 52082 & 967670 & 52082 \\
\hline
\end{tabular}

The dependent variable records the number of completed years of schooling. In all regressions, the Young cohort includes individuals of age 6-25, while the old cohort includes individuals of age 26-45. Due to data limitations, Non-poor is constructed differently in the census and DHS sample. In the census regressions the asset index that is used to define the non-poor variable is constructed using four variables: whether there is (any type) of toilet; whether the dwelling is owned by the household; whether there is a finished floor; and whether there is tiles or cement roof. In the DHS sample the asset index is instead constructed using three variables: whether there is (any type) of toilet; whether there is a finished floor; and whether the household owns a radio. For the DHS sample pre-genocide refers to 1992 and post-genocide to 2000, while for the census sample pre-genocide refers to 1991 and post-genocide to 2002. Administrative Fixed Effects are defined at the Province level (there are 12 Provinces in both the DHS and the census samples). Standard errors are instead clustered at the enumeration level for the DHS regressions and at the Commune level for the census regressions. There are 640 enumeration units and 145 Communes in the DHS and census sample, respectively. ${ }^{* * *} \mathrm{p}<0.01,{ }^{* *} \mathrm{p}<0.05,{ }^{*} \mathrm{p}<0.1$. 


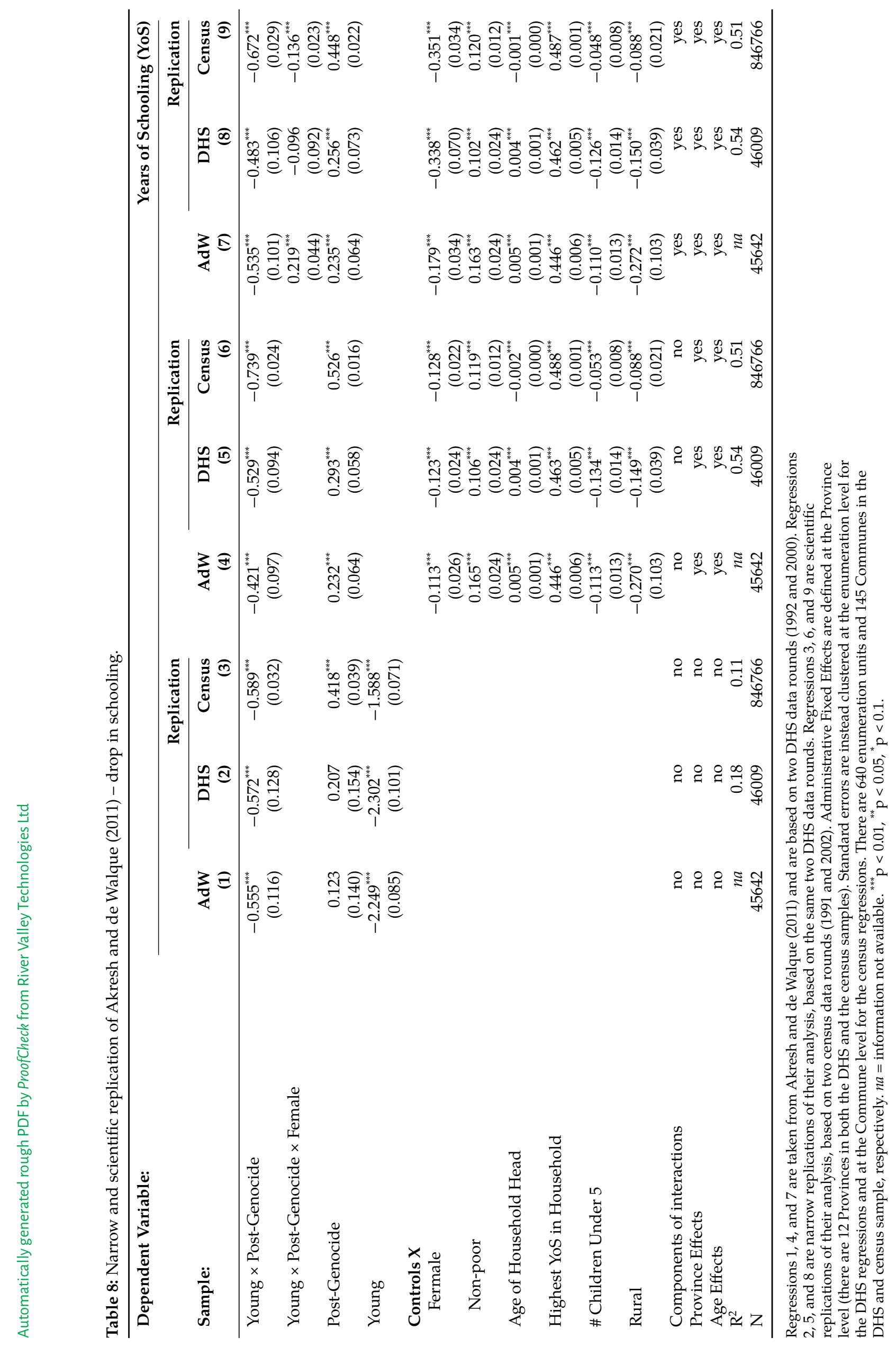




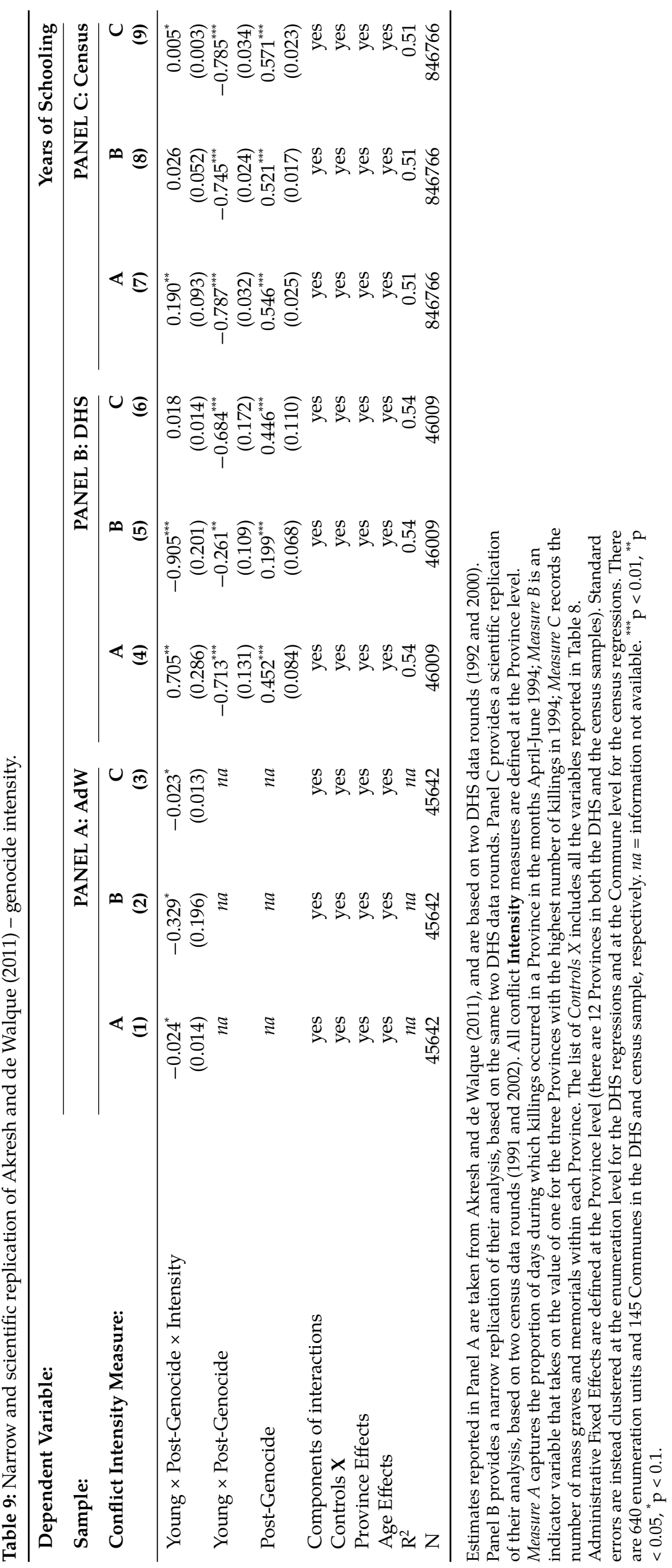




\section{Appendix C}

\section{Sections 5.1 and 5.2-Additional analysis}

In this Appendix we detail a set of robustness checks that we have performed on our main analysis and that are just briefly mentioned in the main text. We start by introducing an alternative definition of the unaffected group, which will be used in some of our checks, and by discussing the corresponding data source. We will then proceed to illustrate and comment the different checks.

\section{Alternative definition of the unaffected group}

In this Appendix we will show the robustness of our findings in an alternative DiD specification, in which we compare the evolution in schooling outcomes experienced by the young cohort in Rwanda with the evolution experienced by young cohorts in three other East African Countries (EAC) - Uganda, Tanzania, and Kenya for which comparable census data is available.

As mentioned in the text, one problem with considering an old cohort to construct the counterfactual for the evolution of schooling attainments in a young cohort is that the two groups start at different places in the distribution of educational attainments. For this reason we also consider an alternative unaffected group, made of a cohort of individual of the same age, but living in other East African countries that did not experience the dramatic violence that Rwanda witnessed over the nineties. There are three countries in which two census rounds were collected around the same years as Rwanda: Uganda (1991 and 2002), Tanzania (1988 and 2002), and Kenya (1989 and 1999). In order to smooth out as much as possible country-specific characteristics, we construct the comparison group by jointly considering the evolution in schooling attainments in these three countries. In this alternative $\mathrm{DiD}$ specification, we consider the young cohort of individuals at schooling age in the different countries and adopt an empirical model similar to Eq. 1:

$$
\left.y_{i, a, c, t}=\beta_{1} \text { (Post-Genocide }_{t} \times \text { Rwanda }_{c}\right)+\beta_{2} \text { Post-Genocide }_{t}+\mathbf{X}_{i, c, t} \Gamma+v_{a}+\lambda_{c}+\mu_{i, a, c, t}
$$

where Rwanda is an indicator variable for living in Rwanda and the fixed effects $\lambda$ comprise administrative units across the different countries considered (indicated with subscript $c$ ). In this case a negative (positive) estimate of the DiD coefficient $\beta_{1}$ indicates that the young cohort in Rwanda in the post-genocide era completed on average less (more) years of schooling, compared to the young cohort in Rwanda in the pre-genocide era and relative to the difference in schooling for the young cohorts in the other EAC countries over the same period.

To study whether the impact was different for girls compared to boys, we slightly modify the above equation, adding a three-way interaction term with the individual-level indicator variable for being female. Concretely,

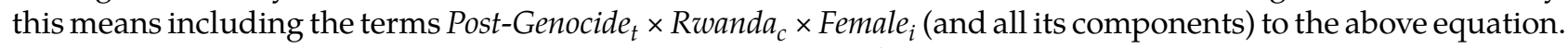

When studying the channels, variations in the structure of the educational system across countries complicate the distinction between primary and secondary schooling. Moreover, differently from years of schooling, outcomes related to the channels are not cumulative and hence there is no risk that young and old cohort start from different points of the distribution. In any case, our results are broadly confirmed when using the comparison with the other EAC countries (see also the discussion in Appendix D).

Ugandan, Tanzanian, and Kenyan population census data

In the three comparison countries, a census was recorded around the beginning of the nineties (1988 for Tanzania, 1989 for Kenya, and 1991 for Uganda) and another around the end (1999 for Kenya, 2002 for both Uganda and Tanzania). IPUMS International provides a random draw from each one of these census rounds (10\% draw for Uganda and Tanzania; $5 \%$ draw for Kenya). Across all the three countries school typically starts at age 6 and is organized in two blocks of primary and secondary school. The main difference is that the primary schooling cycle typically lasts for 7 years, i.e. 1 year longer than in Rwanda, while the full secondary schooling cycle lasts for 4-6 years, depending on the country. Because of country-specific features and events that took place over the nineties, any specific country constitutes only an imperfect comparison for Rwanda. By considering the three countries jointly, we smooth out these country-specific factors.

We use the different census rounds to generate the same variables described in the main text for Rwanda, with minor corrections to the thresholds for the schooling variables to take into account the different length of the primary schooling cycle. The summary statistics, both aggregated and divided by census round, are reported in Panel B of Table $10 .{ }^{30}$ Overall, Table 10 shows that at the beginning of the nineties Rwanda was relatively similar to the average of the other countries in terms of school enrolment in both primary ( $78 \%$ vs. $81 \%)$ and secondary school (16\% vs. $14 \%)$. On the other hand, primary dropout rates were higher in Rwanda 
( $21 \%$ vs. $13 \%$ ), although this is mostly driven by very low rates recorded in Tanzania (7\%). ${ }^{31}$ Figure 10 shows the average completed years of schooling by each age included in the young cohort (6-25), across the two census rounds that are available for the three EAC country: differently from what we observed for Rwanda (Figure 1), during the nineties average schooling attainments improved for each single age.

\section{Section 5.1 - Robustness checks}

We now describe a rich set of additional checks to validate our findings, reported in Sections 5.1. More specifically, we: (i) we perform a falsification check by considering cohorts whose schooling attainments should not have been affected by the genocide; (ii) we enrich the model with commune time trends; (iii) we adjust for post-genocide migration; (iv) we adjust for selective killings during the genocide. (v) we use the evolution in schooling attainments for a young cohort in other EAC countries to construct an alternative counterfactual;

Falsification test

Our DiD estimates, reported in Table 3, indicates that the young cohort in the post-genocide era completed on average 1.1 less years of schooling, compared to the young cohort in the pre-genocide era and relative to the difference in schooling between the old cohorts over the same period. We report this result in column 1 of Table 12. In this baseline approach, identification rests on the assumption that the evolution in schooling attainments for the old age cohort represents a valid counterfactual. To examine the reliability of this assumption we consider two older age cohorts in Rwanda, whose schooling attainments should not have been affected by the genocide. More specifically, we re-estimate Eq. 1 redefining the young cohort to include individuals aged 26-45 (i.e. our previous old cohort) and the old cohort to include individuals aged $46-65 .^{32}$ The DiD coefficient, reported in Column 2, is small (0.24) and, if anything, positive, thus bringing support to our approach.

Time trends

One might worry that the positive coefficient we obtained with the falsification test hints to the presence of a pre-trend, which although "in favor" of our analysis, might affect our estimation. We therefore address this concern by adding a full set of Commune time trends to our model (i.e. for each one of the 145 Communes we create the indicator variable Commune ${ }_{c}$ and we add to the regression the interaction Commune C $_{c} \times$ Post-Genocide $_{t}$ ). Column 3 of Table 12 shows that our results are virtually unaffected by this change (point estimate is -1.103 ).

Migration

Armed conflicts are often associated with large migration flows, both during the conflict and in its aftermath. If especially highly educated adults moved out of the most affected Communes, the gap between the young and old cohort remaining in those Communes would be reduced, thus biasing our DiDiD estimate towards zero. The census data include information on place of birth, previous residence, current residence, and time at current residence, allowing us to trace an individual's migration history. To gauge whether migration is causing a bias we assign all individuals who moved between 1994 and 2002 - representing 16.9\% of the 2002 sample - to their previous Commune of residence and we re-estimate the DiD model. ${ }^{33}$ Column 4 of Table 12 shows that the results are confirmed when applying this correction.

It is also worth noting that while more than 2 million individuals are estimated to have left Rwanda during the violence, the large majority of them returned to their homeland within a few years. By 2002 just about 75,000 refugees were estimated to be still outside the country (UNHCR, 2004). Moreover, by 2002 only $17 \%$ of the population was living in a different District from where their were born, which is very close to the $14 \%$ observed in the 1991 census, suggesting that the large majority of returnees returned to their hometowns.

Selective killings (Differential attrition)

One might still be worried that our results are affected by selective mortality. More specifically, de Walque and Verwimp (2010) show that the probability of being killed in the genocide was highest among the welleducated Tutsi male population. If that's the case, this might lead to a forced drop in the number of educated adults in the 2002 census round, which, if anything, would lead us to underestimate the actual drop in schooling attainments for the young cohort. ${ }^{34}$ As it has been estimated that approximately $75 \%$ of Tutsi were killed during the genocide (Verpoorten, 2005), we gauge whether selective killings might affect our estimates by re-running our regression after removing 75\% of the most educated Tutsi from the 1991 population, i.e. after artificially introducing in the 1991 census a selection similar to the one caused by the genocide. Column 5 of Table 12 shows that our result is virtually unaffected by the correction (point estimate is -1.143).

One additional concern is that the violence might have affected fertility decisions and endogenous fertility response might have caused the younger generation in 1994 to be from families with lower preferences towards education and human capital investment. While we acknowledge the relevance of this channel, we believe this is a minor concern for our analysis, given that children born after the genocide would be only 7 or younger in 2002 and are thus excluded from most of our analysis. Moreover, Figure 2 illustrated that the drop in schooling attainments was not concentrated in the youngest ages. 


\section{EAC countries}

One might still be worried that our main DiD estimates are picking up a peculiarity in the evolution of the Rwandan old age cohorts rather than in the evolution of the young cohort, especially given that the two groups start at different places in the distribution of educational attainment. To address this concern we run Eq. 5, comparing the evolution in the young cohort between Rwanda and the other three EAC countries. Column 6 of Table 12 indicates that in Rwanda individuals aged 6-25 completed 0.94 less years of schooling in the postgenocide era compared to the pre-genocide era and relative to the difference in the other EAC countries over the same period and for the same age group. The similarity between the estimates of $\beta_{1}$ and $\alpha_{1}$, provides support to our empirical strategy. ${ }^{35}$ Moreover, Figure 11 provides a robustness check to this analysis, similar to the one performed in the main analysis (Figure 2). Overall, the figure confirms that our results are robust to minor changes in the specific threshold.

\section{Section 5.2- Boys versus girls}

In Table 3 we also estimated Eq. 1, augmented with the three-way interaction term Post-Genocide $e_{t} \times$ Young $_{a} \times$ Female $_{i}$ (and all its components). The estimated coefficient of the triple interaction term indicated that the drop in schooling was 0.27 years larger for girls than for boys. The result, however, rests on the assumption that, had the violence not taken place, the difference in the 1991-2002 evolution in schooling attainments between girls and boys in the young cohort would have been the same as the difference in the evolution for girls and boys in the old cohort over the same period. This assumption may be questionable, as a catch-up process of girls' schooling had taken off in Rwanda over the previous decade, and this process may have slowed down or accelerated. ${ }^{36}$ Because of this concern, we rerun the analysis dropping the comparison with the old cohort and we consider instead individuals in the young cohort in the other three EAC countries. Concretely, this means estimating Eq. 5 augmented with the three-way interaction term Post-Genocide $e_{t} \times$ Rwand $_{c} \times$ Female $_{i}$ (and all its components). The results reported in column 8 of Table 12 indicate a still significant, but now much smaller drop in schooling for girls compared to boys, equal to 0.1 years. ${ }^{37}$

Overall, results in Panel B clearly indicate that both girls and boys suffered the consequences of the conflicts in Rwanda. The estimates suggest that girls attainments' experienced, if anything, a larger drop, although the difference is small and varies with the exact definition of the comparison group.

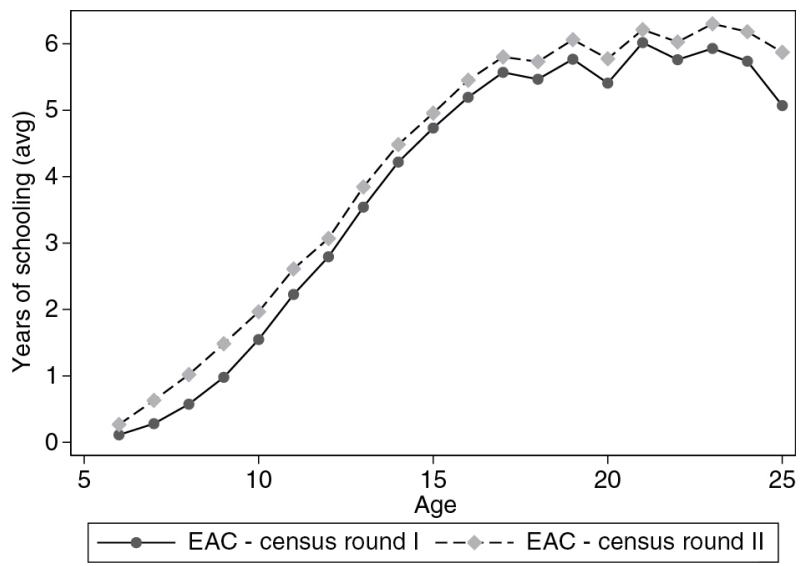

Figure 10: Years of schooling by age in three East African countries.

Notes: The figure shows the average number of completed years of schooling for each age, from 6 to 25 . The figure combines information from 3 different East African Countries (EAC): Uganda, Tanzania, and Kenya. For each one of these countries two different census rounds were collected around the nineties, although the exact years differ from country to country: 1991 and 2002 for Uganda, 1988 and 2002 for Tanzania, 1989 and 1999 for Kenya. IPUMS international provides a $10 \%$ random draw from each round in Uganda and Tanzania, and a 5\% random draw from each round in Kenya. 

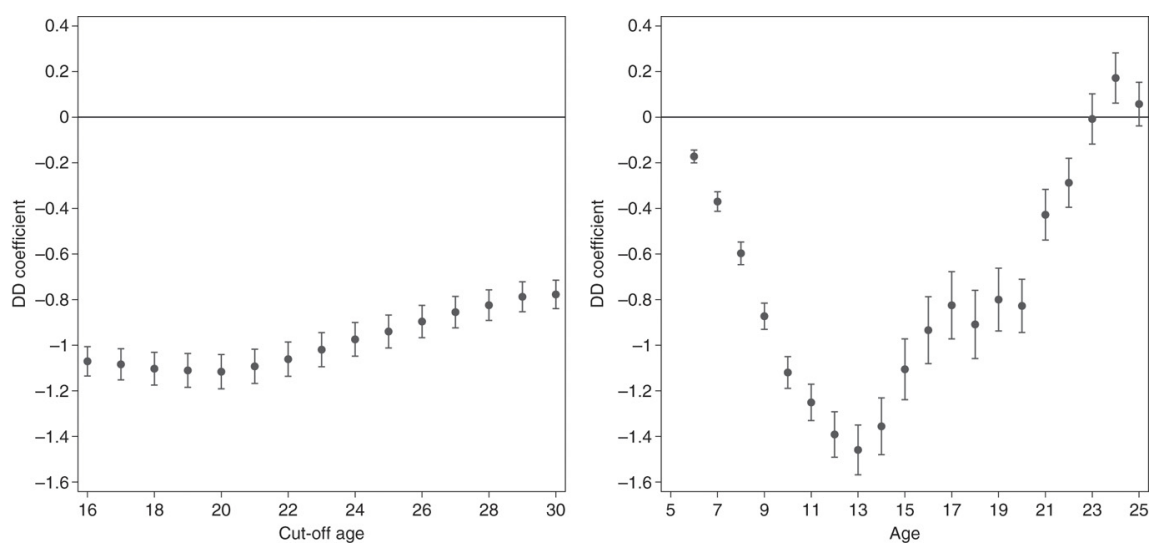

Figure 11: Drop in schooling attainments by Age - comparison with other EAC countries.

Notes: The two figures report the estimates from a set of regressions that are slight modifications of regression 6 in Table 10. The figure on the left shows the point estimates and the $95 \% \mathrm{CI}$ for the DiD coefficients of the interaction term between the Rwanda and the Post-Genocide Round indicators, obtained from different regressions, in which the cut-off separating young and old age cohort moved between 16 and 30 years of age. The figure on the right shows instead the point estimates and the 95\% CI for the DiD coefficients of the interaction term between the Rwanda and the Post-Genocide Round indicators, obtained in different regressions in which only 1 age group was considered at a time.

Table 10: Summary statistics.

\begin{tabular}{|c|c|c|c|c|c|c|c|}
\hline & \multicolumn{5}{|c|}{ Full Sample } & \multirow{2}{*}{$\frac{\text { Round I }}{\text { Mean }}$} & \multirow{2}{*}{$\frac{\text { Round II }}{\text { Mean }}$} \\
\hline & Obs & Mean & Std.dev. & Min & Max & & \\
\hline \multicolumn{8}{|l|}{ A. Rwanda - Young Cohort } \\
\hline Years of Schooling (YoS) & 662,740 & 2.96 & 2.67 & 0 & 16 & 2.94 & 2.98 \\
\hline Post-Genocide Round & 662,740 & 0.52 & 0.5 & 0 & 1 & 0 & 1 \\
\hline Fermale & 662,740 & 0.51 & 0.5 & 0 & 1 & 0.51 & 0.52 \\
\hline Non-poor & 662,740 & 0.63 & 0.48 & 0 & 1 & 0.42 & 0.82 \\
\hline Age of Household Head & 662,740 & 44.12 & 13.98 & 10 & 100 & 44.54 & 43.73 \\
\hline YoS of Household Head & 662,740 & 2.82 & 3.17 & 0 & 16 & 2.58 & 3.04 \\
\hline \# Children Under Five & 662,740 & 1.01 & 0.98 & 0 & 10 & 1.14 & 0.88 \\
\hline Rural & 662,740 & 0.86 & 0.32 & 0 & 1 & 0.87 & 0.85 \\
\hline Student & 502,702 & 0.36 & 0.48 & 0 & 1 & 0.33 & 0.4 \\
\hline Ever Been to Primary School & 502,702 & 0.81 & 0.39 & 0 & 1 & 0.78 & 0.83 \\
\hline Ever Been to Secondary School & 502,702 & 0.13 & 0.34 & 0 & 1 & 0.16 & 0.11 \\
\hline Dropped out from Primary & 502,702 & 0.26 & 0.44 & 0 & 1 & 0.21 & 0.3 \\
\hline Dropped out from Secondary & 502,702 & 0.01 & 0.1 & 0 & 1 & 0.01 & 0.01 \\
\hline \multicolumn{8}{|c|}{ B. Other EA Countries - Young Cohort } \\
\hline Years of Schooling (YoS) & $5,842,773$ & 3.66 & 3.24 & 0 & 16 & 3.44 & 3.79 \\
\hline Post-Genocide Round & $5,842,773$ & 0.61 & 0.49 & 0 & 1 & 0 & 1 \\
\hline Fermale & $5,842,773$ & 0.51 & 0.5 & 0 & 1 & 0.52 & 0.51 \\
\hline Non-poor & $5,842,773$ & 0.63 & 0.48 & 0 & 1 & 0.73 & 0.57 \\
\hline Age of Household Head & $5,842,773$ & 42.59 & 15.23 & 6 & 98 & 42.83 & 42.43 \\
\hline YoS of Household Head & $5,842,773$ & 4.58 & 3.9 & 0 & 16 & 3.79 & 5.08 \\
\hline \# Children Under Five & $5,842,773$ & 1.26 & 1.24 & 0 & 16 & 1.41 & 1.16 \\
\hline Rural & $5,842,773$ & 0.73 & 0.4 & 0 & 1 & 0.74 & 0.72 \\
\hline Student & $4,365,342$ & 0.46 & 0.5 & 0 & 1 & 0.42 & 0.48 \\
\hline Ever Been to Primary School & $4,365,342$ & 0.84 & 0.36 & 0 & 1 & 0.81 & 0.86 \\
\hline Ever Been to Secondary School & $4,365,342$ & 0.16 & 0.37 & 0 & 1 & 0.14 & 0.18 \\
\hline Dropped out from Primary & $4,365,342$ & 0.13 & 0.34 & 0 & 1 & 0.13 & 0.13 \\
\hline Dropped out from Secondary & $4,365,342$ & 0.02 & 0.14 & 0 & 1 & 0.02 & 0.02 \\
\hline
\end{tabular}


Notes: Panel A reports summary statistics for the Young Cohort (ages 6-25) in the Rwandan sample. Panel B reports summary statistics for the Young Cohort (ages 6-25) in the sample composed by three other East African Countries: Uganda, Tanzania, and Kenya. Two census rounds have been collected within each country, although in slightly different years: 1991 and 2002 for Rwanda and Uganda; 1989 and 2002 for Tanzania; 1989 and 1999 for Kenya. Post-Genocide Round is an indicator variables that takes on the value of one for observations included in any of the second census round. Education-related variables are only available for individuals aged 10 or above. Student captures whether the individual reported studying as main occupation. Ever Been to Primary (Secondary) School take on the value of one if the person is enrolled in or completed at least 1 year of Primary (Secondary) school. Dropped out from Primary takes on the value of one if the person completed at least the first year of primary school, but dropped out before completing the full cycle (equal to 6 years for Rwanda and 7 years for the other EAC countries). Dropped out from Secondary takes on the value of one if the person completed at least the first year of secondary school, but dropped out before completing the first 3 years of secondary school (i.e. the lower cycle).

Table 11: Summary statistics by country.

\begin{tabular}{|c|c|c|c|c|c|c|c|}
\hline & \multicolumn{5}{|c|}{ Full Sample } & \multirow{2}{*}{$\frac{\text { Round I }}{\text { Mean }}$} & \multirow{2}{*}{$\begin{array}{r}\text { Round II } \\
\text { Mean }\end{array}$} \\
\hline & Obs & Mean & Std.dev. & Min & Max & & \\
\hline \multicolumn{8}{|l|}{ Panel A. Uganda - Young Cohort } \\
\hline Years of Schooling (YoS) & $1,889,551$ & 3.5 & 3.19 & 0 & 16 & 3.11 & 3.74 \\
\hline Post-Genocide Round & $1,889,551$ & 0.63 & 0.48 & 0 & 1 & 0 & 1 \\
\hline Fermale & $1,889,551$ & 0.51 & 0.5 & 0 & 1 & 0.51 & 0.51 \\
\hline Non-poor & $1,889,551$ & 0.76 & 0.43 & 0 & 1 & 0.7 & 0.8 \\
\hline Age of Household Head & $1,889,551$ & 41.87 & 15.1 & 10 & 95 & 41.77 & 41.94 \\
\hline YoS of Household Head & $1,889,551$ & 4.82 & 4 & 0 & 16 & 4.18 & 5.2 \\
\hline \# Children Under Five & $1,889,551$ & 1.33 & 1.23 & 0 & 13 & 1.43 & 1.27 \\
\hline Rural & $1,889,551$ & 0.87 & 0.33 & 0 & 1 & 0.88 & 0.87 \\
\hline Student & $1,392,280$ & 0.5 & 0.5 & 0 & 1 & 0.4 & 0.56 \\
\hline Ever Been to Primary School & $1,392,280$ & 0.84 & 0.36 & 0 & 1 & 0.78 & 0.88 \\
\hline Ever Been to Secondary School & $1,392,280$ & 0.18 & 0.39 & 0 & 1 & 0.14 & 0.21 \\
\hline Dropped out from Primary & $1,392,280$ & 0.21 & 0.41 & 0 & 1 & 0.26 & 0.19 \\
\hline Dropped out from Secondary & $1,392,280$ & 0.03 & 0.17 & 0 & 1 & 0.02 & 0.03 \\
\hline \multicolumn{8}{|l|}{ Panel B. Tanzania - Young Cohort } \\
\hline Years of Schooling (YoS) & $2,754,921$ & 3.58 & 3.22 & 0 & 15 & 3.42 & 3.68 \\
\hline Post-Genocide Round & $2,754,921$ & 0.62 & 0.49 & 0 & 1 & 0 & 1 \\
\hline Fermale & $2,754,921$ & 0.52 & 0.5 & 0 & 1 & 0.52 & 0.52 \\
\hline Non-poor & $2,754,921$ & 0.48 & 0.5 & 0 & 1 & 0.73 & 0.32 \\
\hline Age of Household Head & $2,754,921$ & 43.15 & 15.53 & 10 & 98 & 43.52 & 42.93 \\
\hline YoS of Household Head & $2,754,921$ & 4.32 & 3.7 & 0 & 15 & 3.35 & 4.91 \\
\hline \# Children Under Five & $2,754,921$ & 1.26 & 1.27 & 0 & 15 & 1.42 & 1.15 \\
\hline Rural & $2,754,921$ & 0.6 & 0.4 & 0 & 1 & 0.6 & 0.59 \\
\hline Student & $2,060,771$ & 0.4 & 0.49 & 0 & 1 & 0.37 & 0.43 \\
\hline Ever Been to Primary School & $2,060,771$ & 0.82 & 0.38 & 0 & 1 & 0.8 & 0.83 \\
\hline Ever Been to Secondary School & $2,060,771$ & 0.12 & 0.32 & 0 & 1 & 0.09 & 0.14 \\
\hline Dropped out from Primary & $2,060,771$ & 0.07 & 0.26 & 0 & 1 & 0.07 & 0.08 \\
\hline Dropped out from Secondary & $2,060,771$ & 0.01 & 0.1 & 0 & 1 & 0.01 & 0.01 \\
\hline \multicolumn{8}{|l|}{ Panel C. Kenya - Young Cohort } \\
\hline Years of Schooling (YoS) & $1,198,301$ & 4.07 & 3.36 & 0 & 15 & 3.95 & 4.16 \\
\hline Post-Genocide Round & $1,198,301$ & 0.58 & 0.49 & 0 & 1 & 0 & 1 \\
\hline Fermale & $1,198,301$ & 0.51 & 0.5 & 0 & 1 & 0.51 & 0.51 \\
\hline Non-poor & $1,198,301$ & 0.77 & 0.42 & 0 & 1 & 0.76 & 0.78 \\
\hline Age of Household Head & $1,198,301$ & 42.42 & 14.7 & 6 & 97 & 42.88 & 42.08 \\
\hline YoS of Household Head & $1,198,301$ & 4.8 & 4.13 & 0 & 15 & 4.14 & 5.29 \\
\hline \# Children Under Five & $1,198,301$ & 1.15 & 1.17 & 0 & 16 & 1.36 & 0.99 \\
\hline Rural & $1,198,301$ & 0.8 & 0.4 & 0 & 1 & 0.84 & 0.77 \\
\hline Student & 912,291 & 0.53 & 0.5 & 0 & 1 & 0.57 & 0.49 \\
\hline Ever Been to Primary School & 912,291 & 0.89 & 0.31 & 0 & 1 & 0.88 & 0.9 \\
\hline Ever Been to Secondary School & 912,291 & 0.24 & 0.43 & 0 & 1 & 0.25 & 0.23 \\
\hline Dropped out from Primary & 912,291 & 0.13 & 0.34 & 0 & 1 & 0.1 & 0.15 \\
\hline Dropped out from Secondary & 912,291 & 0.02 & 0.16 & 0 & 1 & 0.03 & 0.02 \\
\hline
\end{tabular}


The table reports the summary statistics separately for the three different East African Countries considered in the analysis: Uganda, Tanzania, and Kenya. The two census rounds are collected at slightly different years for the different countries: 1991 and 2002 for Uganda; 1989 and 2002 for Tanzania; 1989 and 1999 for Kenya. Post-Genocide Round is an indicator variables that takes on the value of one for observations included in any of the second census rounds. Education-related variables are only available for individuals aged 10 or above. Student captures whether an individual reports studying as main occupation. Ever Been to Primary School and Ever Been to Secondary School takes on the value of one if the person is enrolled in or completed at least 1 year of Primary or Secondary school, respectively. Dropped out from Primary takes on the value of one if the person completed at least the first year of primary school but dropped out before completing the full cycle (equal to 7 years for the three countries). Dropped out from Secondary takes on the value of one if the person completed at least the first year of secondary school but dropped out before completing 3 years of secondary school.

Table 12: Drop in years of schooling.

\begin{tabular}{|c|c|c|c|c|c|c|c|c|}
\hline \multirow{3}{*}{$\begin{array}{l}\text { Dependent } \\
\text { Variable: } \\
\text { Model: }\end{array}$} & \multicolumn{8}{|c|}{ Years of Schooling (YoS) } \\
\hline & & & & & & PANEL A & \multicolumn{2}{|r|}{ PANEL B } \\
\hline & Base & Falsif. & Trends & Migration & Attrition & EAC & & \\
\hline Young Cohort: & $6-25$ & $26-45$ & $6-25$ & $6-25$ & $6-25$ & $6-25$ & $6-25$ & $6-25$ \\
\hline Old Cohort: & $26-45$ & $46-65$ & $26-45$ & $26-45$ & - & $26-45$ & $26-45$ & - \\
\hline & (1) & (2) & (3) & (4) & (5) & (6) & (7) & (8) \\
\hline Young $\times$ & $-1.105^{* * *}$ & $0.241^{* * *}$ & $-1.103^{* * *}$ & $-1.076^{* * *}$ & $-1.143^{* * *}$ & & $-0.996^{* * *}$ & \\
\hline Post-Genociae & $(0.031)$ & $(0.020)$ & (0.031) & (0.029) & $(0.032)$ & & $(0.039)$ & \\
\hline $\begin{array}{l}\text { Rwanda } \times \\
\text { Post-Genocide }\end{array}$ & & & & & & $-0.940^{* * *}$ & & $-0.890^{* * *}$ \\
\hline $\begin{array}{l}\text { Young } \times \\
\text { Post-Genocide } \times \\
\text { Female }\end{array}$ & & & & & & $(0.037)$ & $-0.265^{* * *}$ & $(0.038)$ \\
\hline $\begin{array}{l}\text { Rwanda } \times \\
\text { Post-Genocide } \times \\
\text { Female }\end{array}$ & & & & & & & $(0.029)$ & $-0.098^{* * *}$ \\
\hline $\begin{array}{l}\text { Components of } \\
\text { interactions }\end{array}$ & no & no & no & no & no & no & yes & $\begin{array}{r}(0.020) \\
\text { yes }\end{array}$ \\
\hline Admin Effects & yes & no & yes & yes & yes & yes & yes & yes \\
\hline Age Effects & yes & yes & yes & yes & yes & yes & yes & yes \\
\hline $\mathrm{R}^{2}$ & 0.39 & 0.63 & 0.39 & 0.39 & 0.39 & 0.53 & 0.40 & 0.53 \\
\hline $\mathrm{N}$ & 967678 & 423784 & 967678 & 927867 & 937532 & 6505513 & 967678 & 6505513 \\
\hline Sample & Rwanda & Rwanda & Rwanda & Rwanda & Rwanda & $\begin{array}{r}\text { Rwanda } \\
\text { \& EAC }\end{array}$ & Rwanda & $\begin{array}{r}\text { Rwanda } \\
\text { \& EAC }\end{array}$ \\
\hline
\end{tabular}

The dependent variable records the number of completed years of schooling. PANEL A investigates the overall drop in years of schooling attainments. PANEL B investigates heterogeneity by gender. In regressions 1-5 and regression 7 the sample is restricted to Rwanda and the key comparison is between a Young and an old age cohort. In regressions 5 and 7 the sample includes also three other East African Countries (Uganda, Tanzania, and Kenya) for which census data were collected around the same years. Regressions in PANEL B also include all constitutive terms of the triple interaction, but coefficients are omitted for reasons of space. Post-Genocide is an indicator variables that takes on the value of one for observations included in the 2002 census rounds. Non-poor is an indicator variable for living in a household whose asset index is above the population mean.Robust standard errors in parentheses, clustered at the administrative unit level. There are 145 administrative units (Communes) in the Rwanda sample and 368 administrative units (Communes or Districts) in the sample that includes also the other EAC countries. ${ }^{* * *} \mathrm{p}<0.01,{ }^{* *} \mathrm{p}<0.05,{ }^{*} \mathrm{p}<0.1$.

Table 13: Drop in schooling by country.

\begin{tabular}{|c|c|c|c|c|c|c|c|c|}
\hline \multirow{3}{*}{$\begin{array}{l}\text { Dependent } \\
\text { Variable: }\end{array}$} & \multicolumn{8}{|c|}{ Years of Schooling (YoS) } \\
\hline & \multirow[b]{2}{*}{ (1) } & \multirow[b]{2}{*}{ (2) } & \multirow[b]{2}{*}{ (3) } & \multicolumn{2}{|r|}{ PANEL A } & \multicolumn{2}{|r|}{ PANEL B } & \multirow[b]{2}{*}{ (8) } \\
\hline & & & & (4) & (5) & (6) & (7) & \\
\hline \multirow{2}{*}{$\begin{array}{l}\text { Rwanda } \times \\
\text { Post-Genocide }\end{array}$} & $-0.940^{* * *}$ & $-1.102^{* * *}$ & $-0.867^{* * *}$ & $-0.605^{* * *}$ & $-0.890^{* * *}$ & $-1.005^{* * *}$ & $-0.857^{* * *}$ & $-0.530^{* * *}$ \\
\hline & $(0.037)$ & $(0.055)$ & $(0.034)$ & $(0.032)$ & $(0.038)$ & $(0.059)$ & $(0.035)$ & $(0.036)$ \\
\hline
\end{tabular}


Rwanda $\times$

Post-Genocide $\times$

Female

\begin{tabular}{|c|c|c|c|c|c|c|c|c|}
\hline Post-Genocide & $\begin{array}{c}0.194^{* * *} \\
(0.029)\end{array}$ & $\begin{array}{c}0.424^{* * *} \\
(0.046)\end{array}$ & $\begin{array}{c}0.139^{* * *} \\
(0.026)\end{array}$ & $\begin{array}{r}-0.163^{* * *} \\
(0.025)\end{array}$ & $\begin{array}{c}(0.020) \\
0.112^{* * *} \\
(0.029)\end{array}$ & $\begin{array}{c}(0.027) \\
0.286^{* * *} \\
(0.049)\end{array}$ & $\begin{array}{c}(0.019) \\
0.096^{* * *} \\
(0.025)\end{array}$ & $\begin{array}{r}(0.035) \\
-0.270^{* * *} \\
(0.028)\end{array}$ \\
\hline Controls X & & & & & & & & \\
\hline Fermale & $\begin{array}{r}-0.186^{* * *} \\
(0.025)\end{array}$ & $\begin{array}{r}-0.326^{* * *} \\
(0.051)\end{array}$ & $\begin{array}{r}-0.086^{* * *} \\
(0.012)\end{array}$ & $\begin{array}{r}-0.089^{* * *} \\
(0.029)\end{array}$ & $\begin{array}{r}-0.296^{* * *} \\
(0.032)\end{array}$ & $\begin{array}{r}-0.583^{* * *} \\
(0.074)\end{array}$ & $\begin{array}{r}-0.135^{* * *} \\
(0.018)\end{array}$ & $\begin{array}{r}-0.212^{* * *} \\
(0.055)\end{array}$ \\
\hline Non-poor & $\begin{array}{c}0.493^{* * *} \\
(0.014)\end{array}$ & $\begin{array}{c}0.474^{* * *} \\
(0.018)\end{array}$ & $\begin{array}{c}0.431^{* * *} \\
(0.015)\end{array}$ & $\begin{array}{c}0.628^{* * *} \\
(0.029)\end{array}$ & $\begin{array}{c}0.493^{* * *} \\
(0.014)\end{array}$ & $\begin{array}{c}0.474^{* * *} \\
(0.018)\end{array}$ & $\begin{array}{l}0.431^{* * *} \\
(0.015)\end{array}$ & $\begin{array}{l}0.628^{* * *} \\
(0.029)\end{array}$ \\
\hline $\begin{array}{l}\text { Age of Household } \\
\text { Head }\end{array}$ & $0.019^{* * *}$ & $0.020^{* * *}$ & $0.017^{* * *}$ & $0.020^{* * *}$ & $0.019^{* * *}$ & $0.020^{* * *}$ & $0.017^{* * *}$ & $0.020^{* * *}$ \\
\hline & $(0.000)$ & $(0.001)$ & $(0.000)$ & $(0.001)$ & $(0.000)$ & $(0.001)$ & $(0.000)$ & $(0.001)$ \\
\hline $\begin{array}{l}\text { YoS of Household } \\
\text { Head }\end{array}$ & $0.192^{* * *}$ & $0.213^{* * *}$ & $0.188^{* * *}$ & $0.180^{* * * *}$ & $0.192^{* * * *}$ & $0.213^{* * *}$ & $0.188^{* * *}$ & $0.180^{* * *}$ \\
\hline & (0.003) & $(0.005)$ & (0.003) & (0.006) & (0.003) & (0.005) & (0.003) & $(0.006)$ \\
\hline \# Children Under 5 & $\begin{array}{r}-0.080^{* * *} \\
(0.005)\end{array}$ & $\begin{array}{r}-0.080^{* * *} \\
(0.007)\end{array}$ & $\begin{array}{r}-0.067^{* * *} \\
(0.004)\end{array}$ & $\begin{array}{r}-0.083^{* * *} \\
(0.011)\end{array}$ & $\begin{array}{r}-0.080^{* * *} \\
(0.005)\end{array}$ & $\begin{array}{r}-0.079^{* * *} \\
(0.007)\end{array}$ & $\begin{array}{r}-0.067^{* * *} \\
(0.004)\end{array}$ & $\begin{array}{r}-0.083^{* * *} \\
(0.011)\end{array}$ \\
\hline Rural & $\begin{array}{r}-0.487^{* * *} \\
(0.024)\end{array}$ & $\begin{array}{r}-0.719^{* * *} \\
(0.049)\end{array}$ & $\begin{array}{r}-0.455^{* * *} \\
(0.026)\end{array}$ & $\begin{array}{r}-0.463^{* * *} \\
(0.040)\end{array}$ & $\begin{array}{r}-0.487^{* * *} \\
(0.025)\end{array}$ & $\begin{array}{r}-0.723^{* * *} \\
(0.049)\end{array}$ & $\begin{array}{r}-0.455^{* * *} \\
(0.026)\end{array}$ & $\begin{array}{r}-0.462^{* * *} \\
(0.040)\end{array}$ \\
\hline $\begin{array}{l}\text { Components of } \\
\text { interactions }\end{array}$ & no & no & no & no & yes & yes & yes & yes \\
\hline Admin Effects & yes & yes & yes & yes & yes & yes & yes & yes \\
\hline Age Effects & yes & yes & yes & yes & yes & yes & yes & yes \\
\hline$R^{2}$ & 0.53 & 0.48 & 0.53 & 0.53 & 0.53 & 0.48 & 0.53 & 0.53 \\
\hline $\mathrm{N}$ & 6505513 & 2552291 & 3417661 & 1861041 & 6505513 & 2552291 & 3417661 & 1861041 \\
\hline Sample & $\begin{array}{r}\text { Rwanda } \\
\& \text { EAC }\end{array}$ & $\begin{array}{r}\text { Rwanda } \\
\& \\
\text { Uganda }\end{array}$ & $\begin{array}{r}\text { Rwanda } \\
\& \\
\text { Tanzania }\end{array}$ & $\begin{array}{l}\text { Rwanda } \\
\text { \& Kenya }\end{array}$ & $\begin{array}{r}\text { Rwanda } \\
\text { \& EAC }\end{array}$ & $\begin{array}{r}\text { Rwanda } \\
\& \\
\text { Uganda }\end{array}$ & $\begin{array}{r}\text { Rwanda } \\
\& \\
\text { Tanzania }\end{array}$ & $\begin{array}{l}\text { Rwanda } \\
\& \text { Kenya }\end{array}$ \\
\hline
\end{tabular}

The dependent variable records the number of completed years of schooling. PANEL A investigates the overall drop in schooling attainments in Rwanda. PANEL B investigates heterogeneity of the drop by gender. Regressions 1 and 5 replicate regressions 6 and 8 of Table 12, respectively. Regression 3 includes a full list of Commune time trends, meaning that for each one of the 145 Communes in the sample we include the interaction Commune $\times$ Post-Genocide. In regression 4 all individuals who moved between 1994 and $2002-$

representing $16.9 \%$ of the 2002 sample - are assigned to their previous location of residence. Regression 5 excludes the $75 \%$ of Tutsi with the highest educational attainments from the 1991 sample. Regressions in PANEL B also include all constitutive terms of the triple interaction, but coefficients are omitted for reasons of space. Robust standard errors in parentheses, clustered at the administrative unit level. There are 145 administrative units (Communes) in the Rwanda sample and a total of 368 administrative units (Communes or Districts) in the sample that includes also the other EAC countries. The remaining administrative units are divided as follows: 38 in the Ugandan sample, 119 in the Tanzanian sample, and 66 in the Kenyan sample. ${ }^{* * *} \mathrm{p}<0.01,{ }^{* *} \mathrm{p}<0.05,{ }^{*} \mathrm{p}<0.1$.

\section{Appendix D}

\section{Section 5.3 - Additional analysis}

In Section 5.3 we performed an empirical analysis on the contribution of enrolment (HP1), dropouts (HP2), and school delays (HP3) in explaining the overall drop in schooling in Rwanda. The findings are reported in the main text and Figure 3 and Figure 4 provide a visual representation of the key insights for primary and secondary schooling, respectively. In this Appendix, we give the details of the underlying regression models and we include additional checks.

As mentioned in the text, we build on the DiD framework, adjusting the age limit of the affected cohort to take into account that enrolment, dropout, and delay decisions affect students of different ages. ${ }^{38}$

\section{Primary schooling}

To estimate the impact of conflicts on primary school enrolment (H1) we rerun Eq. 1, replacing the dependent variable with an indicator variable for being a student or having completed at least 1 year of school in the past. ${ }^{39}$ In this case the affected group should include individuals whose enrolment decision (likely) took place after the 1994 genocide. As primary school in Rwanda starts at age 6, this implies we should include individuals 
that were 6 or younger at the time of the genocide, meaning that they were 14 or younger by 2002. Given that the census only records student status starting from age 10, our young cohort embraces ages from 10 to 14. For consistency with our main analysis, we maintain the standard definition of old cohort, hence dropping individuals of age 15-25. ${ }^{40}$ In line with what emerged from Figure 3, regression 1 of Table 14 reveals a small and statistically insignificant DiD coefficient, indicating that the young cohort in 2002 was not less likely to enroll in primary school compared to the young cohort in 1991 and relative to the difference in enrolments between the old cohorts. To facilitate reading the results, the bottom panel of the table reports the mean of the outcome variable for each one of the four different combinations of age group and census rounds.

Second, we look at the evolution of primary school dropouts (H2) by replacing the dependent variable in Eq. 1 with an indicator variable for dropping out of primary school. In this case we restrict the young cohort to consider individuals of age 13-21, i.e. the cohort that would have normally completed primary school between 1994 and 2002 (cohorts outside that bracket either are still of primary schooling age in 2002, or likely completed primary school before the 1994 genocide - see also Figure 6 for reference). Also in this case we keep the standard old age cohort 26-45, thus dropping age 22-25 from the analysis. ${ }^{41}$ Regression 2 of Table 14 indicates that, conditional on starting primary school, individuals in the 2002 young age cohort were 23 percentage points (pp) more likely to drop out before completing the 6-year cycle, compared to individuals of the same cohort in 1991 and relative to the difference in dropouts between the old cohorts. This figure marks a dramatic increase in the dropout rate, which reached 43\% for the young cohort in 2002.

Finally, to study the case of delays in education (H3) we estimate Eq. 2, which considers the age of the student as dependent variable. For this analysis, we restrict the focus to individuals enrolled in grades 2-6 at the time of the census. ${ }^{42}$ As in this case we are interested right in the age of individuals attending school, we consider all students in the sample - only excluding those younger than 10 because the census does not record their enrolment status. Regression 3 in Table 14 indicates that, on average, students enrolled in primary school in 2002 were almost 2 years older than students in the same grade in 1991.

Overall, Panel A of Table 14 confirms what emerged from the figures presented in the main text: students do not enroll less in primary school as a consequence of the conflict, and the large reduction in schooling attainments is caused by both an increase in dropouts and slower grade progression.

\section{Secondary schooling}

We now replicate this analysis for secondary schooling. ${ }^{43}$ We start again by considering school enrolment and we consider as dependent variable an indicator for ever attending secondary school (approximated by an indicator for either being enrolled in or completing at least 1 year of secondary school). In this case the affected group is represented by individuals likely to begin secondary school after the 1994 genocide, i.e. individuals that turned 14 after 1994, meaning that they were $14-22$ by $2002 .{ }^{44}$ Results are reported in Panel B of Table 14. Regression 4 indicates a large and significant drop in secondary school enrolment of 11.5 pp. However, this result is likely to be affected by the significant increase in primary dropout rates documented above. In regression 5 we therefore repeat the analysis restricting the focus on students that actually completed primary school. The DiD coefficient turns now positive, indicating that, if anything, individuals among the 2002 young cohort that completed primary school were more likely to enroll in secondary school (by $4.9 \mathrm{pp}$ ), compared to the same cohort in 1991 and relative to the difference in enrolment between the old cohorts.

We next look at secondary school dropout rates. As mentioned in Section 2.1, in Rwanda the full secondary school cycle lasts for 6 years, but there is the possibility of obtaining a first certificate after 3 years (post-primary cycle). In regression 6 we therefore look at actual dropouts within the first 3 years of secondary school, in order to avoid simply picking up changes in preferences for the type of secondary education cycle. ${ }^{45}$ In this case we define the affected cohort to include individuals likely to have completed the 3 years of secondary school after 1994, i.e. individuals aged 17-25 by 2002. The estimate reported in regression 6 indicates a significant increase (4.6 pp) in dropouts within the first 3 years of secondary school.

Finally, we look at grade progression in secondary school. Similarly to what we did for primary school, we run Eq. 2 restricting the analysis to students enrolled in grades 7-13 and considering the full sample. Regression 7 indicates that students enrolled in secondary school are on average 0.7 years older in the post-genocide era compared to the pre-genocide era. Despite being still significant, this age difference is less than half of the one we estimated for primary schooling, suggesting a smaller increase in school delays for students going to secondary school. ${ }^{46}$ 


\section{Heterogeneity by gender}

We also re-run the same analysis, both for primary and secondary schooling, investigating potential heterogeneity by gender. When studying enrolment (H1) and dropouts (H2), we do so by running a DiDiD model, enriching the specification with a triple interaction Post-Genocide $t \times$ Young $_{a} \times$ Female $_{i}$, (as well as all its constitutive components). When studying school delays (H3) we instead augment Eq. 2 with the interaction Post-Genocide $_{t} \times$ Female $_{i}$. Results of the analysis are reported in Table 16, which mirrors the structure and age choices described for Table 14.

Concerning primary school, the estimates highlight that girls suffer both a significant drop in the enrolment rate (minus $10 \mathrm{pp}$ ) and a larger increase in the dropout rate (plus $5.5 \mathrm{pp}$ ) compared to boys. There is instead no differential effect across gender in terms of school delays.

When looking at secondary school, the situation is reversed, with girls experiencing both a larger increase in enrolment rates (plus $15 \mathrm{pp}$, when considering only students that completed primary schooling) and lower increase in dropout rates (minus $3.6 \mathrm{pp}$ ) than boys. There seem to be again little difference in terms of school delays, although in this case the estimates report a significant additional delay of 0.17 years for girls compared to boys.

Overall, these results suggest that the larger drop for girls that we estimated in Section 5.2 is entirely driven by a worsening in primary schooling outcomes.

Table 14: Channels.

\begin{tabular}{|c|c|c|c|c|c|c|c|}
\hline \multirow[b]{2}{*}{ Dependent Variable: } & \multicolumn{3}{|c|}{ PANEL A: Primary School } & \multicolumn{4}{|c|}{ PANEL B: Secondary School } \\
\hline & $\begin{array}{l}\text { Been to } \\
\text { School }\end{array}$ & Drop out & $\begin{array}{r}\text { Age } \\
\text { Student }\end{array}$ & $\begin{array}{r}\text { Been to } \\
\text { School (a) }\end{array}$ & $\begin{array}{r}\text { Been to } \\
\text { School (b) }\end{array}$ & Drop out & $\begin{array}{r}\text { Age } \\
\text { Student }\end{array}$ \\
\hline Young Cohort: & $10-14$ & $13-21$ & $10-45$ & $14-22$ & $14-22$ & $17-25$ & $10-45$ \\
\hline Old Cohort: & $26-45$ & $26-45$ & - & $26-45$ & $26-45$ & $26-45$ & - \\
\hline \multicolumn{8}{|l|}{$\begin{array}{l}\text { Mean dependent } \\
\text { variable for: }\end{array}$} \\
\hline Young Cohort 1991 & $82 \%$ & $32 \%$ & 11.5 & $21 \%$ & $43 \%$ & $12 \%$ & 15.5 \\
\hline Young Cohort 2002 & $88 \%$ & $43 \%$ & 12.9 & $14 \%$ & $53 \%$ & $16 \%$ & 17.7 \\
\hline Old Cohort 1991 & $58 \%$ & $56 \%$ & . & $7 \%$ & $26 \%$ & $19 \%$ & \\
\hline Old Cohort 2002 & $65 \%$ & $43 \%$ & & $12 \%$ & $32 \%$ & $19 \%$ & \\
\hline
\end{tabular}

Individuals aged below 10 are always excluded from the analysis, because information on student status is only available from age 10. In regression 1 the dependent variable is an indicator taking on the value of one if the individual is enrolled in or completed at least 1 year of school. In regression 2 the dependent variable is an indicator taking on the value of one if the individual dropped out from primary school before completing the 6-years cycle; the sample is restricted to individuals that completed at least 1 year of primary school. In regression 3 the dependent variable is the age of the student; the sample is restricted to students enrolled in grades 2-6. In regression 4 the dependent variable is an indicator taking on the value of one if the individual is enrolled in or completed at least 1 year of secondary school. In regression 5 the dependent variable is the same as in regression 4 , but the sample is restricted to individuals that completed primary school. In regression 6 the dependent variable is an indicator taking on the value of one if the individual dropped out from secondary school before completing 3 years of study (lower cycle); the sample is restricted to individuals that completed at least 1 year of secondary school. In regression 7 the dependent variable is the age of the student; the sample is restricted to students enrolled in grades 7-13. The list of Controls $X$ includes all the variables reported in Table 3 in the main text. Robust standard errors in parentheses, clustered at the administrative unit level. There are 145 administrative units (Communes) in the sample. ${ }^{* * *} p<0.01,{ }^{* *} p<0.05,{ }^{*} p<0.1$.

Table 15: Channels - different age cohort specifications.

\begin{tabular}{|c|c|c|c|c|}
\hline \multirow[b]{2}{*}{ Dependent Variable: } & \multicolumn{2}{|r|}{ Primary } & \multicolumn{2}{|r|}{ Secondary } \\
\hline & Been to school & Drop out & Been to School & Been to School \\
\hline Young Cohort: & 10-14 & 13-21 & $14-22$ & $14-22$ \\
\hline Old Cohort: & $15-45$ & $22-45$ & $23-45$ & $23-45$ \\
\hline \multicolumn{5}{|c|}{ Mean dependent variable for: } \\
\hline Young Cohort 1991 & $82 \%$ & $32 \%$ & $21 \%$ & $43 \%$ \\
\hline Young Cohort 2002 & $88 \%$ & $43 \%$ & $14 \%$ & $53 \%$ \\
\hline Old Cohort 1991 & $66 \%$ & $50 \%$ & $8 \%$ & $27 \%$ \\
\hline Old Cohort 2002 & $74 \%$ & $43 \%$ & $12 \%$ & $32 \%$ \\
\hline
\end{tabular}


Individuals aged below 10 are always excluded from the analysis, because information on student status is only available from age 10. In regression 1 the dependent variable is an indicator taking on the value of one if the individual is enrolled in or completed at least 1 year of school. In regression 2 the dependent variable is an indicator taking on the value of one if the individual dropped out from primary school before completing the 6-years cycle; the sample is restricted to individuals that completed at least 1 year of primary school. In regression 3 the dependent variable is an indicator taking on the value of one if the individual is enrolled in or completed at least 1 year of secondary school. In regression 4 the dependent variable is the same as in regression 4 , but the sample is restricted to individuals that completed primary school. The list of Controls $X$ includes all the variables reported in Table 3 in the main text. Robust standard errors in parentheses, clustered at the administrative unit level. There are 145 administrative units $\left(\right.$ Communes) in the sample. ${ }^{* * *} \mathrm{p}<0.01,{ }^{* *} \mathrm{p}<$ $0.05,{ }^{*} \mathrm{p}<0.1$.

Table 16: Channels - heterogeneity by gender.

\begin{tabular}{|c|c|c|c|c|c|c|c|}
\hline \multirow[b]{2}{*}{ Dependent Variable: } & \multicolumn{3}{|c|}{ PANEL A: Primary School } & \multicolumn{4}{|c|}{ PANEL B: Secondary School } \\
\hline & $\begin{array}{l}\text { Been to } \\
\text { School }\end{array}$ & Drop out & $\begin{array}{r}\text { Age } \\
\text { Student }\end{array}$ & $\begin{array}{r}\text { Been to } \\
\text { School (a) }\end{array}$ & $\begin{array}{r}\text { Been to } \\
\text { School (b) }\end{array}$ & Drop out & $\begin{array}{r}\text { Age } \\
\text { Student }\end{array}$ \\
\hline Young Cohort: & 10-14 & $13-21$ & $10-45$ & $14-22$ & $14-22$ & $17-25$ & $10-45$ \\
\hline \multirow[t]{2}{*}{ Old Cohort: } & $26-45$ & $26-45$ & - & $26-45$ & $26-45$ & $26-45$ & - \\
\hline & (1) & (2) & (3) & (4) & (5) & (6) & (7) \\
\hline \multirow{2}{*}{$\begin{array}{l}\text { Young } \times \text { Post-Genocide } \\
\times \text { Female }\end{array}$} & $-0.100^{* * *}$ & $0.055^{* * *}$ & & $0.063^{* * *}$ & $0.150^{* * *}$ & $-0.036^{* *}$ & \\
\hline & $(0.005)$ & $(0.006)$ & & $(0.005)$ & $(0.011)$ & $(0.014)$ & \\
\hline \multirow[t]{2}{*}{ Young $\times$ Post-Genocide } & $0.048^{* * *}$ & $0.204^{* * *}$ & & $-0.148^{* * *}$ & -0.011 & $0.062^{* * *}$ & \\
\hline & $(0.006)$ & $(0.007)$ & & $(0.006)$ & $(0.012)$ & $(0.008)$ & \\
\hline \multirow[t]{2}{*}{ Female $\times$ Young } & $0.180^{* * *}$ & $-0.045^{* * *}$ & & $-0.039^{* * *}$ & $-0.175^{* * *}$ & $0.036^{* * *}$ & \\
\hline & $(0.005)$ & $(0.006)$ & & $(0.004)$ & $(0.007)$ & $(0.009)$ & \\
\hline \multirow{2}{*}{$\begin{array}{l}\text { Female } \times \\
\text { Post-Genocide }\end{array}$} & $0.111^{* * *}$ & $-0.030^{* * *}$ & $-0.038^{*}$ & $-0.034^{* * *}$ & $-0.118^{* * *}$ & $0.048^{* * *}$ & $0.172^{* * *}$ \\
\hline & $(0.004)$ & $(0.005)$ & $(0.020)$ & $(0.003)$ & $(0.006)$ & $(0.011)$ & $(0.050)$ \\
\hline \multirow[t]{2}{*}{ Post-Genocide } & $-0.025^{* * *}$ & $-0.077^{* * *}$ & $1.898^{* * *}$ & $0.036^{* * *}$ & $0.065^{* * *}$ & 0.003 & $0.646^{* * *}$ \\
\hline & $(0.003)$ & $(0.005)$ & $(0.031)$ & $(0.003)$ & $(0.006)$ & $(0.007)$ & $(0.045)$ \\
\hline Controls X & yes & yes & yes & yes & yes & yes & yes \\
\hline Admin Effects & yes & yes & yes & yes & yes & yes & yes \\
\hline Age Effects & yes & yes & no & yes & yes & yes & no \\
\hline Grade Effects & no & no & yes & no & no & no & yes \\
\hline $\mathrm{R}^{2}$ & 0.28 & 0.15 & 0.28 & 0.19 & 0.25 & 0.10 & 0.46 \\
\hline $\mathrm{N}$ & 487465 & 427100 & 129532 & 590659 & 198681 & 65391 & 50638 \\
\hline
\end{tabular}

Individuals aged below 10 are always excluded from the analysis, because information on student status is only available from age 10. In regression 1 the dependent variable is an indicator taking on the value of one if the individual is enrolled in or completed at least 1 year of school. In regression 2 the dependent variable is an indicator taking on the value of one if the individual dropped out from primary school before completing the 6-years cycle; the sample is restricted to individuals that completed at least 1 year of primary school. In regression 3 the dependent variable is the age of the student; the sample is restricted to students enrolled in grades $2-6$. In regression 4 the dependent variable is an indicator taking on the value of one if the individual is enrolled in or completed at least 1 year of secondary school. In regression 5 the dependent variable is the same as in regression 4, but the sample is restricted to individuals that completed primary school. In regression 6 the dependent variable is an indicator taking on the value of one if the individual dropped out from secondary school before completing 3 years of study (lower cycle); the sample is restricted to individuals that completed at least 1 year of secondary school. In regression 7 the dependent variable is the age of the student; the sample is restricted to students enrolled in grades 7-13. The list of Controls $X$ includes all the variables reported in Table 3 in the main text. Robust standard errors in parentheses, clustered at the administrative unit level. There are 145 administrative units (Communes) in the sample. ${ }^{* * *} \mathrm{p}<0.01,{ }^{* *} \mathrm{p}<0.05,{ }^{*} \mathrm{p}<0.1$.

\section{Appendix E}

\section{Section 5.4-Additional analysis}

In Section 5.4 we performed a DiDiD to assess the relation between the subnational variation in the drop in schooling and the subnational variation in the intensity of the 1994 genocide. We looked at five different proxies for genocide intensity, plus a sixth one obtained as the combination of the other five through Principal Component Analysis. The details and sources of each one of these variables are reported in Table 17, which also includes information on the Non-Genocide Excess Mortality Index (non-GEMI) and the share of households that resettled from Burundi, Tanzania, or DRC - i.e. the two variables unrelated to genocide intensity. 
Table 18 report the pair-wise correlations across the different measures, while Figure 12 shows the geographical distribution of each variable across the different Communes by quantile, with darker colors indicating higher intensity of the violence.

Results reported in Table 4 in the main text showed no link between the within-country distribution of the drop in schooling and the subnational intensity of the genocide. Our results could however be confounded by a number of factors related to the distribution of genocide intensity across the country. In this Appendix, we provide more details about how we address five main potential sources of bias threatening our DiDiD specification ${ }^{47}$; (i) enrich the model with commune time trends; (ii) adjust for postgenocide migration; (iii) adjust for selective killings during the genocide; (iv) adjust for relief programs in the post-genocide period; and (v) use the young cohorts in the other EAC countries to construct an alternative counterfactual.

Time trends

First, conflict intensity could be related to pre-war trends in schooling. This would be the case if for instance areas in which relatively more (or less) Tutsi were located were experiencing different paths in educational attainments before the genocide. In order to control for this, we exploit the large size of our dataset and add a full set of Commune time trends to the DiDiD regression model (i.e. for each one of the 145 Communes we create the indicator variable Commune $e_{c}$ and we add to the regression the interaction Commune ${ }_{c} \times$ Post-Genocide $_{t}$ ).

Migration

Second, armed conflicts are often associated with large migration flows, both during the conflict and in its aftermath. If especially highly educated adults moved out of the most affected Communes, the gap between the young and old cohort remaining in those Communes would be reduced, thus biasing our DiDiD estimate towards zero. The census data include information on place of birth, previous residence, current residence, and time at current residence, allowing us to trace an individual's migration history. To gauge whether migration is causing a bias we assign all individuals who moved between 1994 and 2002 - representing $16.9 \%$ of the 2002 sample - to their previous Commune of residence and we re-estimate the DiDiD model. ${ }^{48}$

Selective killings (Differential attrition)

Third, de Walque and Verwimp (2010) demonstrate that the probability of being killed in the genocide was relatively higher for men, for the well-educated, and for Tutsi, and was highest among the well-educated Tutsi male population. The targeted killing of Tutsi adults could thus bias downward our DiDiD estimates, since it would reduce the gap between the schooling of the young and old age cohorts in the post-genocide population in the Provinces and Communes with high genocide intensity. As it has been estimated that approximately 75\% of Tutsi were killed during the genocide (Verpoorten, 2005), we gauge the magnitude of this bias by re-running our estimations after removing $75 \%$ of the most educated Tutsi from the 1991 population, i.e. after artificially introducing in the 1991 census a selection similar to the one caused by the genocide in 1994.

Relief programs

Fourth, in the aftermath of the violence many relief and assistance programs for genocide survivors were launched. One of the largest program is the FARG (Fonds d'Assistance aux Rescapés du Génocide), which by 1998 was awarding scholarships for secondary schooling to 24,000 students, which is a sizeable share of genocide survivors at schooling age. ${ }^{49}$ The support received by genocide survivors may partly confound the link between the intensity of the genocide and the drop in schooling, by lifting educational attainments of the young cohort in genocide affected area (63\% of the beneficiaries of the scholarship are reported to be paternal orphans). The census does not contain any information on scholarship, but can rely on a nationally representative survey collected in 1999/2000 (EICV1), to construct a measure for the share of students receiving the scholarship in each Province. We then assess the potential bias of these scholarships by removing from the young age cohort of each Province a share of the best educated individuals, equal to the Province-level share of students that received a scholarship according to the EICV1 data. ${ }^{50}$

\section{EAC countries}

Fifth, given that most of the potential threats just outlined are induced by the comparison between young and old cohort in differently affected areas, we also switch comparison group and compare the evolution in schooling attainments for the young cohort in Rwanda to the evolution in schooling attainments for the young cohort in the other three EAC countries. More specifically, we run two separate regressions based on Eq. 5, splitting the Rwandan sample between Communes that experienced genocide intensity above the median, and Communes that experienced genocide intensity below the median.

The results of these different tests are reported in Table 20, where we consider the 1994 death rate as conflict proxy. Across all the different tests, the DiDiD coefficient remains statistically insignificant and the DiD coefficients remain very stable, thus confirming that areas more severely affected by the genocide did not experience a more (or less) severe drop in schooling attainments, compared to other areas. Considering any of the other genocide intensity proxies does not affect our conclusion. ${ }^{51}$ 


\section{Additional Figures/Tables in the Appendix}

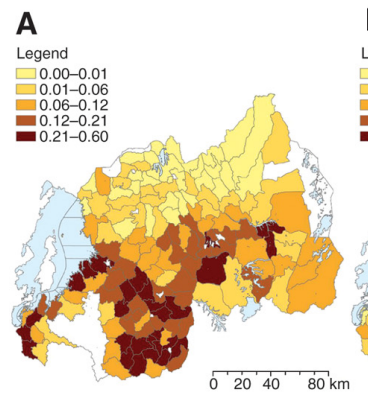

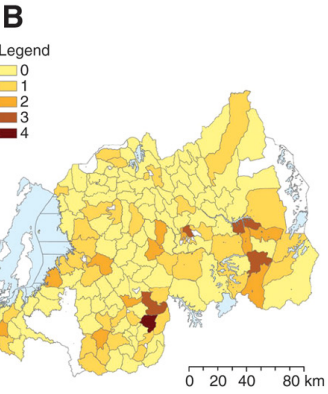

E
D

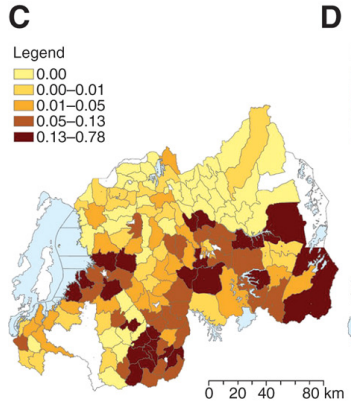

F
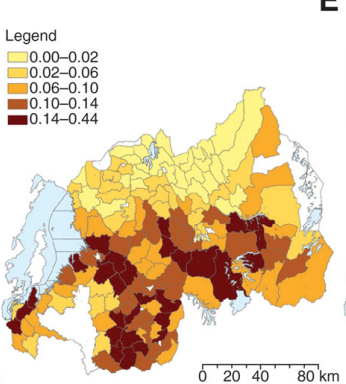

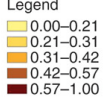

G

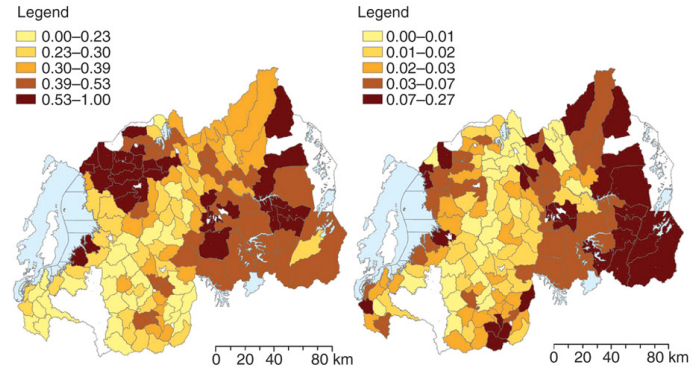

Figure 12: Conflict-related variables - coverage and geographic distribution. (A) Share of Tutsi; (B) \# Massgraves; (C) 1994 Death rate; (D) Prosecution rate; (E) GEMI; (F) non-GEMI; (G) Resettled.

Notes: The figures show the spatial distribution of the different conflict-related measures used in the empirical analysis (see Table 17 for details and sources). For all measures except Figure B different colors identify different quantiles, with darker shades indicating higher intensity. No data are available for areas in white, which mostly include national parks and forests.

Table 17: Conflict-related variables - sources and description.

\begin{tabular}{lll}
\hline Variable & Description & Source \\
\hline Share of Tutsi & $\begin{array}{l}\text { Share of Tutsi living in the Commune in 1991. The variable is available at the } \\
\text { Commune level. }\end{array}$ & $\begin{array}{l}1991 \\
\text { Population } \\
\text { Census }\end{array}$ \\
& $\begin{array}{l}\text { Number of mass graves located within the boundary of an administrative unit. } \\
\text { The variable is available both at the Sector and at the Commune level. }\end{array}$ & $\begin{array}{l}\text { Genocide } \\
\text { Studies }\end{array}$ \\
& & Program at \\
& Yale University
\end{tabular}


Prosecution Rate

1994 Death Rate

Excess Mortality Indexes (GEMI and non-GEMI)
Share of people prosecuted for violent crimes committed during the Rwandan genocide. In 2001 the government of Rwanda set up a court system that relied on the traditional judicial system to prosecute the hundreds of thousand people accused of committing crimes during the 1994 genocide. The suspected criminals were classified in three different categories. In the analysis the nominator captures the sum of individuals included in categories 1 and 2. Category 1 suspects were accused of being planners or leaders during the genocide or of being murderers who distinguished themselves because of the zeal which characterized them in the killings, or of having committed rape and tortures. Category 2 suspects were accused of being killers or of having committed act of physical violence during the genocide. The number of suspects is weighted by the estimated share of Hutu living in the Sector in 1991 (from the Population Census). The natural logarithm is used in the analysis. The variable is available both at the Sector and at the Commune level.

Death rate caused by 1994 political violence, estimated from information collected by the Ministry of Education in Rwanda, Ministry of Local Affairs in Rwanda, Ibuka (the Rwandan survivor organization), African Rights (the international human rights organization) and Human Rights Watch (the international human rights organization). The five data sources are combined and a latent variable model is used to estimate the number of casualties in the Rwandan genocide. See Armstrong (2014) for a detailed description of the methodology. The estimated number of deaths in a Commune is weighted by the population living in the Commune in 1991 (from the Population Census). Communes for which no deaths are reported are assigned value zero. The variable is available at the Commune level.

GEMI (Genocide Excess Mortality Index) and non-GEMI (non-Genocide related Excess Mortality Index) are the first and second principal component of five excess mortality proxies, derived from the 1991 and 2002 population census rounds (the mortality of sons, the mortality of daughters, widowhood, orphanhood, and disability due to war or genocide) and six genocide-specific proxies (the three categories of genocide suspects and three categories of genocide survivors all taken proportional to the 1991 population). All variables enter with positive loadings for GEMI, but not for non-GEMI. Hence, GEMI captures excess mortality related to the genocide, while non-GEMI captures the part of wartime excess mortality that is not associated with genocidal killings. See Verpoorten (2012a) and Serneels and Verpoorten (2015) for further details. The two variables used in the analysis have been standardized to make interpretation easier and are available at the Commune level.

Resettled
(formerly
externally
displaced)

Share of households that resettled from DRC, Tanzania, or Burundi. The measure is constructed as the share of households in which at least one of the two following conditions is satisfied: 1) (at least) one child was born in DRC, Tanzania, or Burundi between 1994 and 1998; 2) the household moved to live in the current location from DRC, Tanzania, or Burundi after 1994. The measure is based on information contained in the 2002 census round. It is estimated that almost 2 million people sought temporary refuge in the camps set up across the border with neighboring countries - especially DRC, Tanzania, and Burundi - during the nineties. These externally displaced individuals only returned to Rwanda at a slow pace from 1996 onwards (UNHCR, 2000). The variable is available both at the Sector and at the Commune level.

National

Service of

Gacaca

Jurisdiction

Genodynamics

Project

1991 and 2002

Population

Census

Rounds

(Serneels \&

Verpoorten, 2015;

Verpoorten, 2012a)

2002 Population

Census

Table 18: Conflict-related measures - summary statistics.

\begin{tabular}{lcrrrr}
\hline & Obs & Mean & Std.dev. & Min & Max \\
\hline A. Commune level & & & & & \\
$\quad$ Share of Tutsi & 145 & 0.13 & 0.13 & 0 & 0.6 \\
\# Massgraves & 145 & 0.48 & 0.8 & 0 & 4 \\
1994 Death Rate & 145 & 0.07 & 0.12 & 0 & 0.78 \\
Prosecution rate & 145 & 0.09 & 0.07 & 0 & 0.44 \\
GEMI & 145 & 0 & 1 & -1.91 & 3.01 \\
non-GEMI & 145 & 0 & 1 & -2.06 & 3.5 \\
$\quad$ Resettled & 145 & 0.07 & 0.1 & 0 & 0.61 \\
B. Sector level & & & & &
\end{tabular}


Share of Tutsi indicates the 1991 share of Tutsi living in the Commune. \# Massgraves counts the number of mass graves located within a Commune. 1994 Death rate refers to the deaths caused by the 1994 political violence and is obtained by combining information from different sources using a latent variable model. Prosecution rate indicates the number of Category 1 and Category 2 suspects for committing crimes during the genocide, weighted by the share of Hutu living in the Commune in 1991. GEMI indicates the Genocide Excess Mortality (standardized) Index and is obtained as the weighted sum of the first differences of five excess mortality proxies taken from the census data, combined with six genocide-specific proxies related to the share of genocide suspects. non-GEMI indicates the non-Genocide Excess Mortality (standardized) Index and captures the part of wartime excess mortality that is not associated with genocidal killings. Resettled indicates the share of households that resettled from DRC, Tanzania, or Burundi after 1994. See Table 17 for more details and sources.

Table 19: Conflict-related variables - correlations.

\begin{tabular}{|c|c|c|c|c|c|c|c|}
\hline & $\begin{array}{r}\text { Share of } \\
\text { Tutsi }\end{array}$ & $\begin{array}{r}\text { \# Mass- } \\
\text { graves }\end{array}$ & $\begin{array}{r}1994 \text { Death } \\
\text { rate }\end{array}$ & $\begin{array}{r}\text { Prosecution } \\
\text { rate }\end{array}$ & GEMI & $\begin{array}{l}\text { non- } \\
\text { GEMI }\end{array}$ & Resettled \\
\hline Share of Tutsi & 1 & & & & & & \\
\hline \# Massgraves & 0.34 & 1 & & & & & \\
\hline 1994 Death Rate & 0.56 & 0.10 & 1 & & & & \\
\hline Prosecution Rate & 0.63 & 0.34 & 0.42 & 1 & & & \\
\hline GEMI & 0.70 & 0.45 & 0.46 & 0.81 & 1 & & \\
\hline non-GEMI & -0.15 & -0.02 & -0.04 & -0.24 & -0.02 & 1 & \\
\hline Resettled & 0.03 & 0.17 & 0.02 & 0.06 & 0.05 & 0.15 & 1 \\
\hline
\end{tabular}

All variables are defined at the Commune level. See Table 17 for details and sources. 


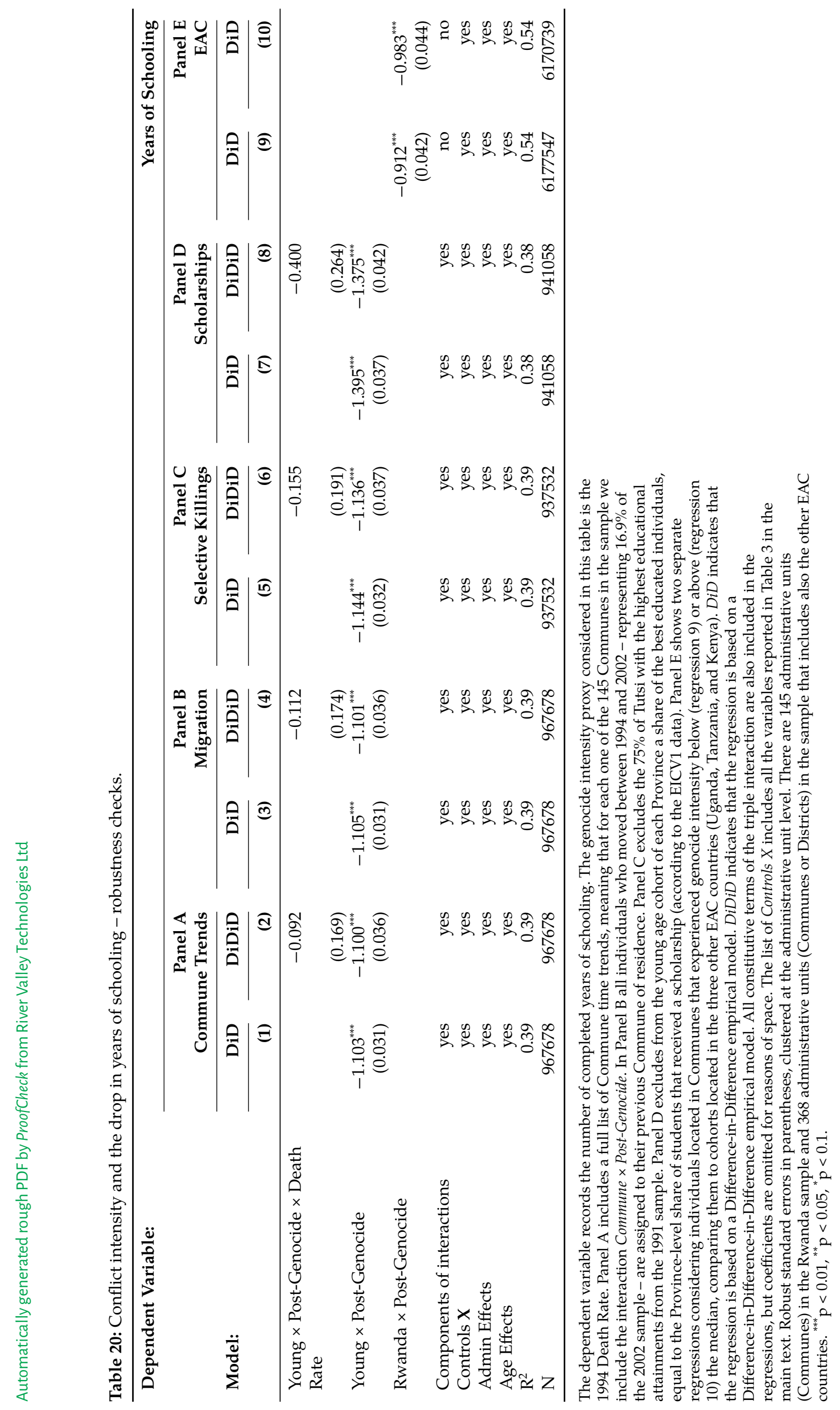




\section{Notes}

1 Most micro-level studies only focus on primary schooling (e.g. Justino, Leone, \& Salardi, 2014). Some make the distinction between the impact on primary versus secondary schooling attainments (e.g. Chamarbagwala \& Morán, 2011; Oyelere \& Wharton, 2013; Rodríguez \& Sanchez, 2012; Shemyakina, 2011; Swee, 2009), without however studying the different channels. To the best of our knowledge, there are only a (limited) number of cross-country studies that rely on aggregated data to look at the impact of conflicts on school enrolment and/or dropouts across primary and secondary schooling (Chen, Loayza, \& Reynal-Querol, 2008; Poirier, 2012; Stewart, Huang, \& Wang, 2001). 2 Similarly to our work, the study by Akresh and de Walque (2011) investigates the impact of conflicts on education in Rwanda relying on a DiD strategy. Despite some overlaps, there are important differences in the data and methodology used in the analysis, which lead to different results. While Akresh and de Walque use DHS data, focus on primary schooling, and rely on province-level conflict measures, we use census data, consider both primary and secondary schooling, and rely on a large set of fine-grained conflict measures. In our empirical analysis we moreover address a likely erroneous specification used by the authors. Because of these differences, our analysis leads to different answers to the overlapping research questions: 1) we identify a significant larger effect of the violence on schooling attainments; 2) we do not find any evidence that boys suffered more than girls; 3 ) we show the impact of armed conflicts to be nationwide and not limited to areas where the violence was more intense. In addition to this, the census data at our disposal allows us to dig deeper into the channels behind the drop in schooling. Appendix A reports the detailed comparison between our analysis and the one of Akresh and de Walque (2011).

3 For a detailed description of the recent history of Rwanda see Mamdani (2001) and Des Forges (1999).

4 For more details on the education system in Rwanda, see World Bank (2004) and Obura (2003).

5 One problem with considering an old cohort to construct the counterfactual for the evolution of schooling attainments in a young cohort is that the two groups start at different places in the distribution of educational attainments. For this reason we also consider an alternative unaffected group, made of a cohort of individual of the same age, but living in other East African countries that did not experience the dramatic violence that Rwanda witnessed over the nineties. All our main results are confirmed when relying on this alternative approach (see Appendix $C$ for details).

6 While the 1991 census only records the Commune of the respondent, the 2002 round records the Sector. There are 145 Communes and 1432 Sectors in the sample.

7 More specifically, the instrument is constructed by interacting the distance between each Sector and the nearest major road with the amount of rain that fell over that path during the 100 days of the genocide. The idea behind this instrument is that rainfall exogenously increased the difficulty of reaching some villages rather than others, as dirt roads became quickly muddy and difficult to cross. We refer to the study by Rogall for more details. It should be noted that Rogall uses this measure to instrument the share of army and militia perpetrators - i.e. Category 1 perpetrators, according to the Gacaca database - in a given Sector, as they are more likely to move from village to village. His analysis, however, shows that the presence of such perpetrators in a Sector leads to a higher number of civilian (or Category 2) perpetrators as well. In this analysis we therefore use the variable to instrument for the total share of Category 1 and Category 2 perpetrators in the Sector.

8 We use the same set of controls used by Rogall (2015).

9 The 1991 10\% sample is made available by IPUMS international, while the 2002 sample has been drawn from the full 2002 census. Among other things, the 1991 census indicates the Commune of residence of each individual. The administrative reform that took place in 2001 changed the 154 Communes in 106 Districts. The 2002 census records both District and Sector of residence of each individual, with the Sector being the lower administrative unit (there were 1536 Sectors in Rwanda by 2002). By merging two administrative maps of Rwanda, we matched each of the 2002 Sectors with the corresponding 1991 Commune.

10 The indicator takes value one when the households' asset index exceeds the population mean of the index. The asset index is constructed by giving equal weight to four variables indicating whether: the dwelling is owned by the household; there is (any type) of toilet; there is finished floor; there is tiles or cement roof.

11 The measure is actually called CEMI in the original source (Verpoorten, 2012a), although it formally captures all non-genocide related excess mortality over the nineties.

12 Between 1991 and 2002 the average years of schooling for the cohort of females aged $26-45$ increased by $43 \%$, moving from 2.3 years to 3.3 years. This compares to a $20 \%$ increase for males, for which average schooling attainments increased from 3.5 to 4.2 years.

13 Delays can be caused either by students postponing education or by students repeating the same class more than once. We are unable to disentangle these two factors with the data at our disposal.

14 We exclude grade 1 because there are very few students enrolled in the first class of primary school aged 10 or above.

15 These findings are broadly confirmed when we re-run the analysis considering the alternative comparison group represented by the young cohort in the three other EAC countries. However, in this case the comparison is complicated by differences in the structure of the schooling systems across countries. For this reason, estimates are not discussed in details, but are available on request.

16 Similar mismatches emerge with other genocide intensity proxies, whose geographical distributions are reported in Appendix E.

17 In a cross-country analysis Lai and Thyne (2007) show that civil wars are devastating for a country education system through the loss of infrastructure and personnel that they cause.

18 The EICV1 surveyed about 6,500 households and records whether there is any operating primary school within the community of the respondent and whether any renovation or reconstruction works took place at the school since 1994. Overall the survey covers 439 Sectors, located in 139 Communes. Works were recorded in $16 \%$ of these Sectors. In a regression analysis framework, we find that communities in areas more affected by (any form of) violence were equally likely to be in the proximity of an operating primary school, and not more likely to have been the location of reconstruction or renovation works of a school building since 1994.

19 Results available on request.

20 Figure 9 provides additional suggestive evidence of this interpretation, showing that within the population of students enrolled in school at the time of the census rounds, the distribution is more skewed towards students that only recently enrolled in school in 2002, compared to 1991.

21 Appendix A includes a direct comparison of our analysis with the work by Akresh and de Walque (2011).

22 Information contained in a nationally representative survey collected in 1999/2000 (EICV1), indicates that less than 5\% of the students enjoyed a scholarship in the Northern Provinces, compared to more than $12 \%$ in some of the Central and Southern Provinces.

23 In our analysis we constructed the index by giving equal weights to four different household-level indicator variables: whether there is (any type) of toilet; whether the dwelling is owned by the household; whether there is finished floor; and whether there is tiles or cement roof. As we cannot exactly match these variables in the DHS data, we build an index that combines three variables: whether there is (any type) of toilet; whether there is finished floor; and whether the household owns a radio. 
24 Akresh and de Walque's study exists as an IZA discussion paper (IZA DP No. 3516, 2008), a World Bank Policy Research Paper (WPS4606, 2008), and a Households in Conflict Network Paper (HiCN Working Paper 47, 2008). The version we refer to is the latest update that is currently available, dated February 2011.

25 AdW combine six different asset variables: whether the household has piped running water, refrigerator, radio, finished floor, bicycle, motorcycle, and car. Whenever performing the narrow replication of their results, based on DHS data, we replicate the same measure; however, when performing the scientific replication based on the census data, we are forced to stick to our original asset index, based on four asset variables (whether the dwelling is owned by the household, whether there is any type of toilet, whether there is finished floor, and whether there is tiles or cement roof).

26 The imperfect match in the estimate is likely due to the small difference in the number of observations in the sample. In our sample we indeed have 367 observations more than AdW, although it is not clear where this difference comes from.

27 For completeness, AdW report finding similar results when using alternative cutoff ages for the young and old cohorts. In a footnote, they report re-defining the young cohort as aged 6-12, 6-18, 6-21, and 6-24; and the old cohort as aged 16-25, 16-30, 16-40, 16-45, 16-50, and 16-55.

28 Measure A and B are taken from the genodynamics project (Davenport \& Stam, 2009); measure C is taken from the Yale Genocide Studies website (http://www.yale.edu/gsp/rwanda/)

29 Results are not reported, but available on request. We do not discuss them in detail because we believe the exclusion restriction is unlikely to hold. To defend the choice for the instrument, the authors argue that Provinces close to the border with Uganda were reached faster by the RPF, who stopped the killings perpetrated by the militia, and therefore these Provinces are more likely to be low conflict intensity Provinces. Although this instrument is relevant, it is unlikely to be exogenous, as distance from the borders is likely to be correlated with a number of alternative additional factors related to educational attainments (for instance, the Southern part of the country was also characterized by a higher concentration of Tutsi, which traditionally enjoyed higher levels of education).

30 Table 11 reports the statistics disaggregated by the three countries.

31 Figures in Table 10 refer to the full sample. The comparison remains similar when excluding individuals that are too young to be enrolled or to have completed school and when restricting dropouts to individuals that ever attended school: primary and secondary school enrolment rate become respectively $78 \%$ and $19 \%$ in Rwanda, while $81 \%$ and $20 \%$ in the other EAC countries; primary and secondary school dropout rates become instead respectively $32 \%$ and $12 \%$ in Rwanda, while $20 \%$ and $16 \%$ in the other EAC countries.

32 The result is qualitatively the same if we change in the age cohorts chosen for the falsification test. In particular, if we run the falsification test on age groups close to the affected age group of interest (e.g. we compare 26-30 to 31-35), we find a non-statistically significant (p-value 0.475 ) drop of 0.18 years of schooling (results available on request).

33 The 2001 administrative reform decreased the official number of Communes from 154 to 106, changing their name in Districts. While the 2002 census records the Sector of current residence of each individual (which allows matching it to the pre-reform Commune), it only records the previous District of residence. In cases in which a District covers more than one pre-reform Commune we therefore assign the individual to the largest of those Communes. The estimation is however robust to randomly assigning to any of the corresponding Communes as well as to completely dropping migrants from the analysis. Individuals previously living abroad are excluded from the sample.

34 In principle, the selective killing of educated adults is also likely to affect the educational attainments of their surviving children, thus affecting educational attainments of the young cohort as well. We however take this channel explicitly into account in all our regressions, by controlling for the level of education of the household head.

35 Table 13 reports the results when the other EAC countries are considered one at a time.

36 Between 1991 and 2002 the average years of schooling for the cohort of females aged 26-45 increased by $43 \%$, moving from 2.3 years to 3.3 years. This compares to a $20 \%$ increase for males, for which average schooling attainments increased from 3.5 to 4.2 years.

37 Table 13 reports the results when the other EAC countries are considered one at a time.

38 Although we will justify our choices on the basis of the information contained in the 1991 census round, one might still be worried that some thresholds have been chosen ad hoc. Reassuringly, all our results are robust to minor changes in the definition of the thresholds (results are available on request).

39 Even in the presence of binary dependent variables, in our analysis we keep estimating an unrestricted linear probability model because it is more traceable. Results are qualitatively the same when using a Probit model (results available on request).

40 Given that enrolment is sometimes delayed, dropping ages 15-25 also allows us to exclude individuals for which it is unclear whether the enrolment decision was affected by the genocide or not. Table 15, shows that results reported in this Section keep holding whenever the excluded groups are included in the old cohort.

41 Once again, Table 15 shows that the results remain qualitatively similar when the dropped ages are instead included in the old cohort, although in this case the coefficient becomes somewhat smaller. This is due to the fact that a significant share of the students in the excluded cohort were still in primary school at the time the violence exploded (Figure 6 shows that more than $20 \%$ of the students aged 14 were still attending primary school in 1991), and including them in the control group leads therefore to an underestimation of the effect on dropouts. 42 We exclude grade 1 because, as mentioned above, we only have information on the student status for individuals aged 10 or above and in 1991 there are just 189 students enrolled in the first class of primary school aged 10 or above.

43 Because of the large variation in the age at which primary school is completed, it is more difficult to precisely determine at which age students are likely to enroll and complete secondary school. Our results on secondary schooling should therefore be considered with more caution than those for primary schooling. Reassuringly, however, our results are once again robust to small changes in the definition of the thresholds.

44 Figure 6 shows that the majority of the students shifts to secondary school between age 13 and 14 . Table 15 shows that results are similar when the age category $23-25$ is included in the old cohort.

45 While $4.5 \%$ of the overall sample completed 3 years of secondary school (3.7\% in 1991 and $5.3 \%$ in 2002), only $2.3 \%$ completed more than that (1.4\% in 1991 and $3.2 \%$ in 2002).

46 These findings are broadly confirmed when we re-run the analysis considering the alternative comparison group represented by the young cohort in the three other EAC countries. The only significant difference relates to the fact that this new comparison highlights a significant drop also in primary school enrolment, although its magnitude (4.6 percentage points) is relatively small compared to the prevailing primary enrolment rate ( $88 \%$ in 2002 in Rwanda) and compared to the importance of primary dropouts and delays. It should be stressed that the comparison in this case is complicated by differences in the structure of the schooling systems across countries. For this reason, estimates are not discussed in details, but they are available from the authors.

47 A sixth additional concern is that the violence might have affected fertility decisions and endogenous fertility response might have caused the younger generation in 1994 to be from families with lower preferences towards education and human capital investment. While we acknowledge the relevance of this channel, we believe this is a minor concern for our analysis, given that children born after the genocide would be only 7 or younger in 2002 and are thus excluded from most of our analysis. Moreover, Figure 2 illustrates that the drop in schooling attainments was not concentrated in the youngest ages. 
48 As explained in the main text, the 2001 administrative reform decreased the official number of Communes from 154 to 106 , changing their name in Districts. While the 2002 census records the Sector of current residence of each individual (which allows matching it to the pre-reform Commune), it only records the previous District of residence. In cases in which a District covers more than one pre-reform Commune we therefore assign the individual to the largest of those Communes. The estimation is however robust to randomly assigning to any of the corresponding Communes as well as to completely dropping migrants from the analysis. Individuals previously living abroad are excluded from the sample.

49 It is estimated that in total 300,000 Tutsi survived (Prunier, 1998) - among which about 20\% would have been at secondary schooling age in 1998. Information on the FARG can be found on their website www.farg.gov.rw.

50 For instance, since $14 \%$ of students are reported to receive a scholarship in Gitarama Province, compared to $5 \%$ in Gisenyi Province, we drop from the sample $14 \%$ of the best educated children in the young cohort in Gitarama Province and 5\% in Gisenyi Province.

51 The only difference is that when using other proxies the DiDiD coefficient in Panel D (i.e. scholarships) turns sometimes weakly significant, although the DiD coefficient remains always very stable and significant, leaving our interpretation overall unaffected (results not reported, but available from the authors).

\section{References}

African Rights. (1998). Rwanda: The Insurgency in the North-West. African Rights.

Agüero, J. M., \& Majid, M. F. (2014). War and the Destruction of Human Capital. HiCN Working Paper 163.

Akbulut-Yuksel, M. (2014). Children of war the long-run effects of large-scale physical destruction and warfare on children. Journal of Human Resources, 49(3), 634-662.

Akresh, R., \& de Walque, D. (2011). Armed conflict and schooling: evidence from the 1994 rwandan genocide. Update of IZA Discussion Paper 2008 3516, Institute for the Study of Labor (IZA). Available at: http://faculty.las.illinois.edu/akresh/ (Accessed: February 2018).

Amnesty International. (1996-1998). Amnesty International Reports. Amnesty International.

Armstrong, D. (2014). Explanation of Rwanda Data Methodology. Mimeo.

Blattman, C., \& Miguel, E. (2010). Civil war. Journal of Economic Literature, 48(1), 3-57.

Bruck, T., Di Maio, M., \& Miaari, S. (2013). Exposure to violence and student achievement in palestine: evidence from the second intifada. DiW BerlinWorking Paper, Berlin, Cermany.

Buvinić, M., Das Gupta, M., \& Shemyakina, O. N. (2014). Armed conflict, gender and schooling. World Bank Economic Review, 28(2), 311-319.

Chamarbagwala, R., \& Morán, H. E. (2011). The human capital consequences of civil war: Evidence from Cuatemala. Journal of Development Economics, 94(1), 41-61.

Chen, S., Loayza, N. V., \& Reynal-Querol, M. (2008). The aftermath of civil war. World Bank Economic Review, 22(1), $63-85$.

Davenport, C., \& Stam, A. (2009). Rwandan Political Violence in Space and Time. Mimeo.

Des Forges, A. (1999). Leave none to tell the story: genocide in Rwanda. New York: Human Rights Watch.

de Walque D., \& Verwimp, P. (2010). The demographic and socio-economic distribution of excess mortality during the 1994 genocide in Rwanda. Journal of African Economies, 19(2), 141-162.

Dupuy, K., Gates, S., Nygard, H. M., Rudolfsen, I., Rustad, S. A., Strand, H., \& Urdal, H. (2017). Trends in armed conflict, 1946—2016. Conflict Trends, Oslo: Peace Research Institute Oslo (PRIO).

Guariso, A., \& Verpoorten, M. (2014). Aid, trade, and post-war recovery of the Rwandan coffee sector. Journal of Eastern African Studies 12, $552-$ 574.

Justino, P. (2011). Violent conflict and human capital accumulation. HiCN Working Paper 99.

Justino, P., Leone, M., \& Salardi, P. (2014). Short and long-term impact of violence on education: the case of timor leste. World Bank Economic Review, 28, 320-353.

Lai, B., \& Thyne, C. (2007). The effect of civil war on education, 1980-1997. Journal of Peace Research, 44(43), 277-292.

León, C. (2012). Civil conflict and human capital accumulation: the long term effects of political violence in Peru. Journal of Human Resources, 47(4), 991-1023.

Lopez, H., \& Wodon, Q. (2005). The economic impact of armed conflict in Rwanda. Journal of African Economies, 14(4), 586-602.

Lucas, R. E., Jr. (1988). On the mechanics of economic development. Journal of Monetary Economics, 22(1), 3-42.

Mamdani, M. (2001). When victims become killers: colonialism, nativism, and the genocide in Rwanda. Princeton: Princeton University Press.

Mincer, J. (1974). Schooling, experience and earnings. New York: National Bureau of Economic Research.

MINEPRISEC/MINESUPRES. (1994). Actes du séminaire sur l'assistance d'urgence et la reconstruction du système éducatifau Rwanda. Kigali, Rwanda: MINEPRISEC/MINESUPRES.

Obura, A. (2003). Never Again: education reconstruction in Rwanda. Paris: UNESCO - International Institute for Educational Planning.

Oyelere, R. U., \& K. Wharton. (2013). The impact of conflict on education attainment and enrolment in Colombia: lessons from recent IDPS. HiCN Working Paper 141.

Poirier, T. (2012). The effects of armed conflict on schooling in Sub-Saharan Africa. International Journal of Educational Development, 32, $341-351$.

Prunier, G. (1998). The Rwanda crisis: history of a genocide. New York: Columbia University Press.

Rodríguez, C., \& Sanchez, F. (2012). Armed conflict exposure, human capital investments, and child labor: evidence from Colombia. Defence and Peace Economics, 23(2), 161-184.

Rogall, T. (2015). Mobilizing the masses for genocide. Mimeo. http://cega.berkeley.edu/assets/miscellaneous_files/60_-ABCAROCALL_Rwanda.pdf.

Rogall, T., \& Yanagizawa-Drott, D. (2014). The legacy of political mass killings: evidence from the Rwandan genocide. Mimeo.

Serneels, P., \& Verpoorten, M. (2015). The impact of armed conflict on economic performance: evidence from Rwanda. Journal of Conflict Resolution, 59(4), 555-592. 
Shemyakina, O. N. (2011). The effect of armed conflict on accumulation of schooling: results from Tajikistan. Journal of Development Economics, 95(2), 186-200.

Singh, P. \& Shemyakina, O. N. (2016). Cender-differential effects of terrorism on education: the case of the Punjab insurgency $1981-1993$. Economics of Education Review, 54, 185-210.

Stewart, F., Huang, C., \& Wang, M. (2001). Internal wars in developing countries: An empirical overview of economic and social consequences. In F. Stewart, \& V. Fitzgerald (eds.), War and underdevelopment. Oxford: Oxford University Press.

Straus, S. (2006). The order of genocide: race, power, and war in Rwanda. Ithaca, USA: Cornell University Press.

Swee, E. L. (2009). On war and schooling attainment: the case of Bosnia and Herzegovina. HiCN Working Paper 57.

UNESCO. (2010). The hidden crisis: Armed conflict and education. Think piece commissioned for the EFA Clobal Monitoring Report 2011, Montreal, Canada: UNESCO Institute for Statistics.

UNHCR. (2000). The State of the World's Refugees 2000: Fifty Years of Humanitarian Action in the Rwandan Cenocide and its Aftermath. Oxford: Oxford University Press.

UNHCR. (2004). UNHCR Statistical Yearbook 2002. Geneva, Switzerland: United Nations High Commissioner for Refugees (UNHCR).

Verpoorten, M. (2005). The death toll of the Rwandan genocide: a detailed study for Gikongoro Province. Population, 60(4), 331-368.

Verpoorten, M. (2012a). The intensity of the Rwandan genocide: Fine measures from the Gacaca records. Peace Economics, Peace Science and Public Policy, 18(1), 1-26.

Verpoorten, M. (2012b). Leave None to claim the land: a malthusian catastrophe in Rwanda? Journal of Peace Research, 49(4), 547-563.

Verpoorten, M. (2012c). Detecting hidden violence: the spatial distribution of excess mortality in Rwanda. Political Ceography, 31(1), 44-56.

Verwimp, P. (2005). An economic profile of peasant perpetrators of genocide: micro-level evidence from Rwanda. Journal of Development Economics, 77(2), 297-323.

World Bank. (2004). Education in Rwanda - rebalancing resources to accelerate post-conflict development and poverty reduction. Washington, DC: The World Bank.

Yanagizawa-Drott, D. (2014). Propaganda and conflict: evidence from the Rwandan Cenocide. Quarterly Journal of Economics, 129(4), 19471994. 